\title{
Renewable Electricity Grid Integration Roadmap for Mexico: Supplement to the IEA Expert Group Report on Recommended Practices for Wind Integration Studies
}

August 2015

B. Parsons

Evergreen Renewable Consulting

J. Cochran, A. Watson, J. Katz, R. Bracho

National Renewable Energy Laboratory

White Paper 


\section{FOREWORD}

\section{About EC-LEDS}

Launched in 2010, Enhancing Capacity for Low Emission Development Strategies (ECLEDS) is a flagship program of the U.S. Global Climate Change initiative. Through the EC-LEDS program, the U.S. government supports partner countries in the design and implementation of low emission development strategies (LEDS) that promote sustainable social and economic development while slowing the growth of greenhouse gas emissions. EC-LEDS builds on existing country programs, plans, and policies, focusing on supporting the unique national development goals of each partner. It also complements efforts of other international donors and organizations to support LEDS. The United States is partnering with over 20 countries under the EC-LEDS program; partner countries benefit from targeted technical support and contribute to the creation of a shared global body of knowledge on LEDS development. 


\section{ACKNOWLEDGMENTS}

The authors express their great appreciation to José Maria Valenzuela, Adrian Cordero Lovera, Luis Gerardo Guerrero Gutierrez, and Fidel Carrasco Gonzalez of SENER for their time, guidance, and sharing of knowledge regarding the renewable energy context in Mexico, and for inviting the National Renewable Energy Laboratory (NREL) to participate in the Special Program for Renewable Energy process.

In addition, the authors would like to thank the Mexico Low Emission Development team at TetraTech and Gina Cady of the U.S. Agency for International Development for her continued support.

Finally the authors would like to thank Melissa Butheau, Doug Arent, Patrick Sullivan, Trieu Mai, and Kendra Palmer of NREL for their contributions. 


\section{LIST OF ABBREVIATIONS AND ACRONYMS}

AGC

CENACE

CFE

CRE

DOE

EC-LEDS

ERCOT

EWEA

GOM

IIE

LAERFTE

LCOE

LEDS

NREL

PCM

PEMEX

PPA

$\mathrm{RE}$

RPM

SENER

UCED

USAID

USG

UVIG automatic generation control

Centro Nacional de Control de Energía (México's ISO)

Federal Electricity Commission

Electric Regulatory Commission

U.S. Department of Energy

Enhancing Capacity for Low Emission Development Strategies

Electric Reliability Council of Texas

European Wind Energy Association

Government of Mexico

Electrical Research Institute

Law on the Use of Renewable Energy and Financing of Energy Transition

Levelized Cost of Energy

Low Emission Development Strategies

National Renewable Energy Laboratory

production cost modeling

Petróleos Mexicanos (Mexico's state owned oil enterprise)

power purchase agreement

renewable energy

resource planning model

(Mexico's) Ministry of Energy

unit commitment and economic dispatch

U.S. Agency for International Development

United States government

Utility Variable-Generation Integration Group 


\section{TABLE OF CONTENTS}

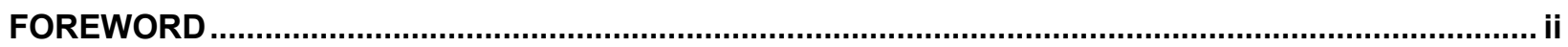

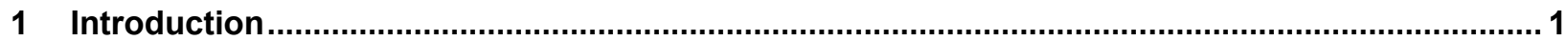

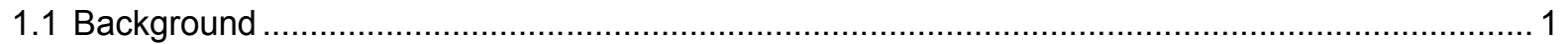

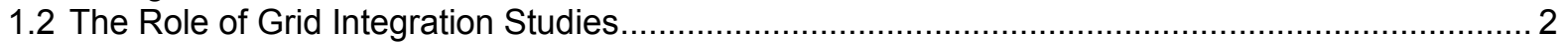

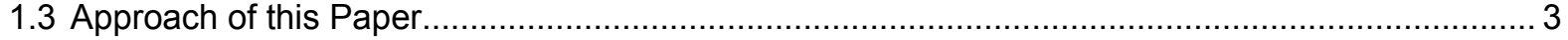

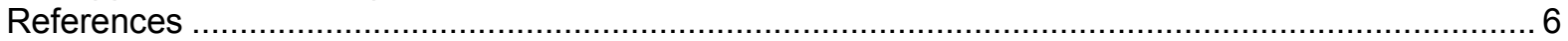

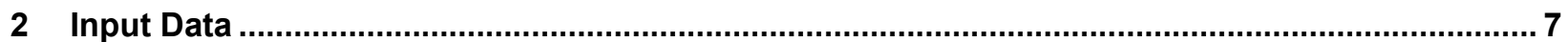

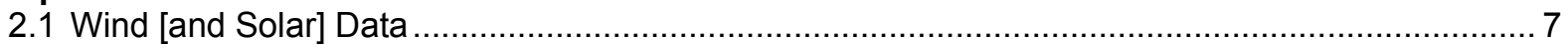

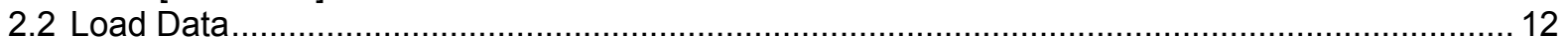

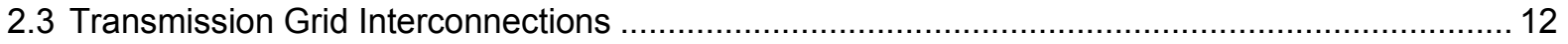

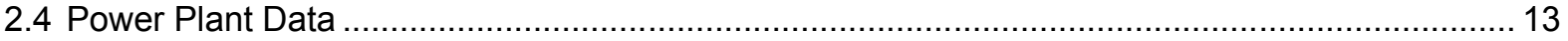

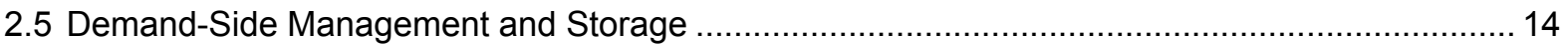

2.6 Mexico-Specific Checklist of Recommendations: Input Data ....................................... 15

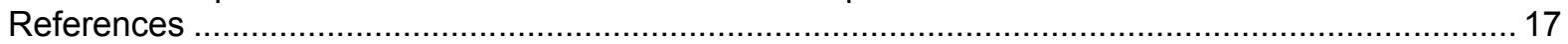

3 Portfolio Development and System Management..................................................................... 19

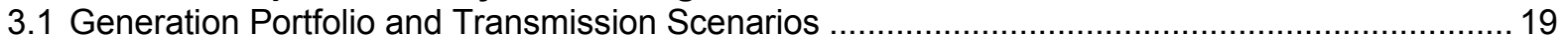

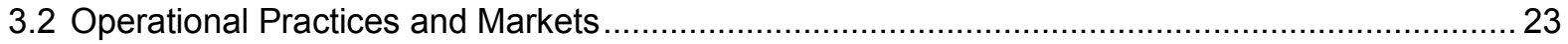

3.3 Reserve Allocation_Estimating Changes Due to Wind Power ....................................... 25

3.4 Mexico-Specific Checklist: Portfolio Development and System Management ........................27

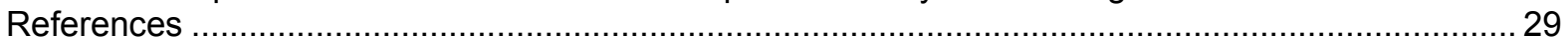

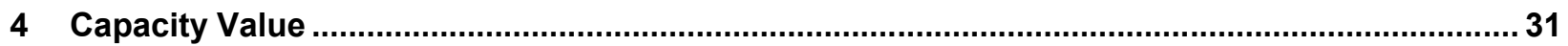

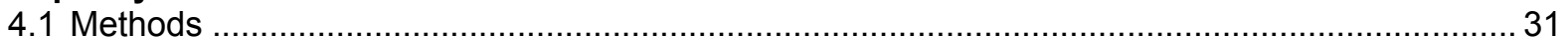

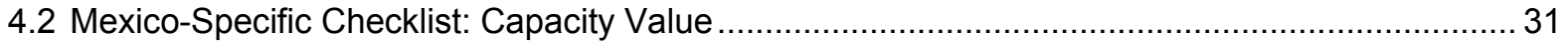

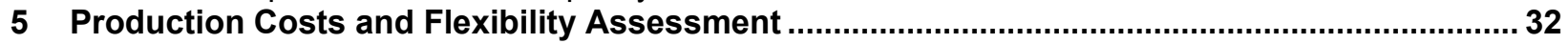

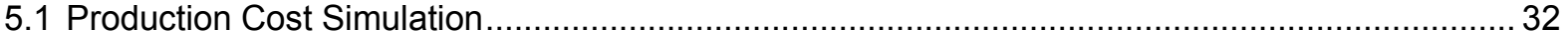

5.2 Flexibility Assessments as a Pre-PCM Screening Tool ................................................. 35

5.3 Mexico-specific Checklist of Recommendations: Production Cost and Flexibility Assessment ... 35

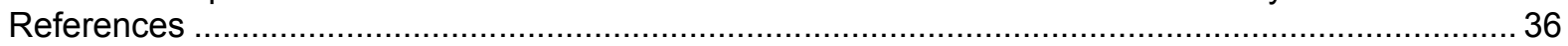

6 Transmission Grid Simulations: Load Flow and Dynamics.......................................................38

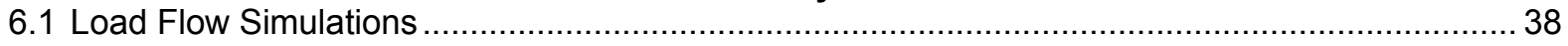

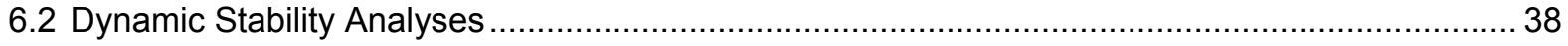

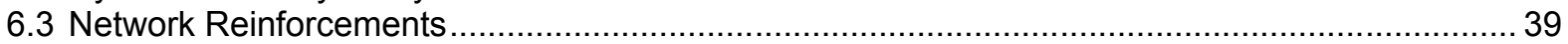

6.4 Mexico-Specific Checklist of Recommendations: Transmission Grid Simulations ......................40

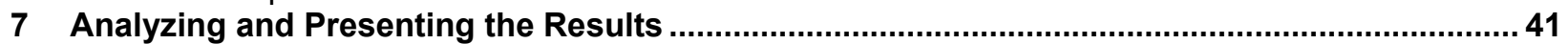

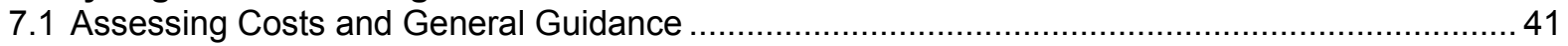

7.2 Mexico-specific Checklist of Recommendations: Analyzing and Presenting Results .............. 42

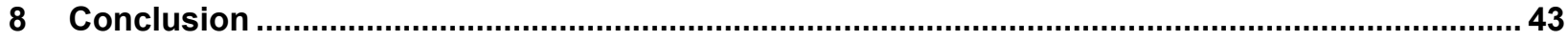

\section{LIST OF FIGURES}

Figure 1. Wind integration study components............................................................................ 5 


\section{Introduction}

As a recognized leader in efforts to mitigate global climate change, the Government of Mexico (GOM) works proactively to reduce emissions, demonstrating strong political will and capacity to comprehensively address climate change. Since 2010, the U.S. government (USG) has supported these efforts by partnering with Mexico under the Enhancing Capacity for Low Emission Development Strategies (EC-LEDS) program. Through the program, the USG has partnered with Mexico's Ministry of Energy (SENER), as well as other government agencies, to support GOM in reaching its clean energy and climate change goals.

Specifically, the EC-LEDS program is supporting GOM's clean energy goal of generating $35 \%$ of its electricity from renewable energy (RE) by 2024. EC-LEDS, through the U.S. Agency for International Development (USAID) and the U.S Department of Energy's (DOE's) National Renewable Energy Laboratory (NREL), has been collaborating with SENER and GOM interagency working group-the Consejo Consultivo para las Energías Renovables (Consultative Council on Renewable Energy) - to create a grid integration roadmap for variable RE. ${ }^{1}$ A key objective in creating a grid integration roadmap is assessing likely impacts of wind and solar energy on the power system and modifying planning and operations accordingly. This paper applies best practices in conducting a grid integration study to the Mexican context.

\section{I.I Background}

The 2008 Mexican Law on the Use of Renewable Energy and Financing of Energy Transition (LAERFTE in Spanish) requires that SENER, under the Special Program for Renewable Energy, set RE goals (installed capacity and minimum generation percentages) for the period of 2014 to 2018 (SENER 2014). The General Law on Climate Change, passed on April 19, 2012, sets a legally binding goal for Mexico of generating $35 \%$ of its electricity from RE by 2024 . While this goal comes to maturity after the time period stipulated by LAERFTE, the Special Program goal for the period between 2014 and 2018 must prepare the nation for meeting the $35 \%$ goal by 2024 . While nuclear and large-scale hydro may make up a portion of the portfolio mix for the $35 \%$ by 2024 goal, LAERFTE specifies that RE generation between 2014 and 2018 will not include nuclear or new large hydro.

In addition to these laws on RE generation, Mexico has recently undertaken electricity sector reform. For the last few decades, Mexico's oil and electricity sectors have been entirely dominated by the state-run petroleum company (PEMEX) and the state-run electricity utility (Federal Electricity Commission [CFE]). Under the reform, private entities and foreign businesses will be able to enter these sectors, conducting oil exploration and extraction or electricity generation in partnership with CFE and PEMEX or independently. Mexico's energy reform first enacted a constitutional reform on December $20^{\text {th }}, 2013$, and by August $11^{\text {th }}, 2014$, the implementing legislation was finally

\footnotetext{
${ }^{1}$ Variable RE-namely wind and solar-refers to RE that cannot be stored prior to electricity generation; therefore, generation output varies based on the intensity of the energy source (e.g., wind speed, sunlight). 
approved. While there will be a second stage of RE, energy efficiency, and sustainability by-laws discussed by Congress during the last quarter of 2014, the basic legislation for the creation of the electric market has already been approved.

With the publication in April 2014 of the Special Program on Renewable Energies 20142018, the federal administration set an ambitious generation target: the percentage of power produced in the country from RE and high-efficiency cogeneration should expand from $14.7 \%$ to $24.9 \%$ from 2012 to 2018 . SENER convened the "Consejo Consultivo para las Energías Renovables" (the Consultative Council on Renewable Energy in English, or "the Council") to consult on establishing the goals and to make recommendations on policies required for realizing those goals. The Council is comprised of the following public institutions (SENER 2013):

- Ministry of Environment

- Ministry of Health

- Ministry of Economy

- Ministry of Finance

- Ministry of Agriculture

- Electric Regulatory Commission (CRE)

- National Commission of the Efficient Use of Electricity

- CFE.

The group also consists of representatives from a number of nongovernmental organizations and industrial associations. SENER leads this group and coordinates analysis, research, and informational workshops that the group will use to draft the Special Programs and forthcoming policies, not only from the energy sector but also from other sectors represented at the Council. In particular, SENER and the Council have sought technical assistance to better understand the technical approaches, grid planning, and studies required to set reasonable RE goals by technology and to plan for any grid implications of integrating variable RE as planned.

With the energy reform, these requirements have become more urgent. One of the key new policies will be the establishment of the Clean Energy Obligations system and a market for tradable clean energy certificates.

\section{I.2 The Role of Grid Integration Studies}

A central objective of operating the power system is providing electric service in the face of variability and uncertainty. Demand for electricity changes continually (and sometimes unpredictably) but usually along daily and seasonal patterns. Supply can also be unpredictable-for example, as a result of a sudden generator outage. The power system accommodates this variability and uncertainty through several mechanisms. Predicted variability is addressed by fluctuating the scheduled output of system generation resources. Unpredicted variability is addressed through frequency 
reserves, such as part-loaded fast response hydro and gas resources on automatic generation control.

Adding variable RE to the power system does not fundamentally change how the system is operated, but the added variability and uncertainty can make the balance of supply and demand more difficult to maintain. At low penetration levels of wind and solar (below $5 \%-10 \%$ of annual electric demand), the added variability and uncertainty is typically small compared to what the power system is designed to address. As RE policy goals become more ambitious, the variability and uncertainty of wind and solar can affect the economics and reliability of power system operations.

To rationally assess challenges and solutions to managing variability and uncertainty, grid operational studies are often commissioned or even administratively required. Staged interaction between RE goal setting and studies of operational feasibility can give policymakers a basis for assessing potential challenges, solutions, and economic impacts of increasing the level of variable RE on the grid. Globally, studies like those described in this roadmap have historically taken place against a much bigger backdrop of electric system innovation, reform, and transformation. Progressive analytic studies of increasing RE penetrations, staged against increasing clean energy goals, allow opportunities for electric grid planners, operators, and regulators to gain experience, formulate creative solutions, and ensure economic and reliable operation of a transformed electric system.

\section{I.3 Approach of this Paper}

In response to SENER's need for capacity building and technical assistance in variable RE grid integration, USAID has supported the development of this document, a renewable electricity grid integration roadmap for Mexico. This roadmap lays out a process for conducting comprehensive integration studies in parallel with gradually increasing RE targets.

This grid integration roadmap is intended to supplement the International Energy Agency (IEA)'s Expert Group Report on Recommended Practices 16. Wind Integration Studies (hereafter referred to as "IEA expert group report"), which was developed by members of Task 25 of the IEA Implementing Agreement for Cooperation in the Research, Development, and Deployment of Wind Energy Systems (Holttinen 2013).

Task 25 is dedicated to the design and operation of power systems with large amounts of wind power. Initiated in 2006, Task 25 is a cooperative effort that aims to provide information to facilitate the highest economically feasible wind energy penetration within electricity power systems worldwide (IEA 2014). Currently, Task 25 contains representatives from 15 countries and the European Wind Energy Association (EWEA). Most member countries' grid operators participate in Task 25 activities. Mexico is a member of IEA Wind, and we recommend that Mexico expand its participation and join 
Task 25 with appropriate representation from SENER, CENACE, CFE, and Instituto de Investigaciones Electricas (IIE). ${ }^{2}$

In September 2013, IEA Wind approved the IEA expert group report. The report preface states:

This IEA Expert Group Report provides recommendations based on more than 8 years of work within International Energy Agency (IEA) Wind Task 25 Design and Operation of Power Systems with Large Amounts of Wind Power. The report is issued as an IEA Wind Recommended Practices document to provide research institutes, consultants, and system operators with the best available information on how to perform a wind integration study. The recommendations will be updated as further work in IEA Wind Task 25 reveals improved integration study methodologies based on real wind integration experiences. This IEA Expert Group Report describes the methodologies, study assumptions, and inputs needed to conduct a wind integration study (Holttinen 2013, p. ii).

The IEA expert group report represents the best available synthesis of current knowledge on conducting large-scale wind integration studies. The recommendations presented in the report are generally applicable to the development of wind integration studies within a variety of country- and/or system-specific contexts. The report also contains a section-by-section reference list of key technical literature that can be used by Mexico stakeholders for further investigation.

The NREL grid integration team assisting Mexico through the EC-LEDS program has prepared this grid integration roadmap in order to contextualize the recommendations in the IEA expert group report specifically to support Mexico's efforts to significantly increase the contribution of RE to the nation's electricity supply. This roadmap highlights and elaborates on the key messages in the IEA expert group report and summarizes recommendations for Mexican electricity system planners. These recommendations are based on NREL's understanding of Mexico's current renewable electricity priorities and status with respect to analyzing grid integration impacts.

The grid integration roadmap in Mexico adopts the same table of contents as the IEA expert group report to facilitate easy reference between the two documents. This structure maps to the flow chart shown in Figure 1, which outlines the process, components, and information flows associated with a wind integration study. To elaborate on each component in Figure 1, the IEA expert group report (and this supplemental document) is organized according to the following sections:

1. Introduction

2. Input data

3. Portfolio development and system management

\footnotetext{
${ }^{2}$ Marco Borja from the IIE is the Mexico representative to IEA Wind. Within IEA Wind, Mexico currently does not participate in Task 25. NREL, U.S. DOE, and the Utility Variable-Generation Integration Group (www.variablegen.org) have grid integration experts participating in Task 25 for the United States.
} 
4. Capacity value

5. Production costs and flexibility assessment

6. Transmission grid simulations: load flow and dynamics

7. Analyzing and presenting the results.

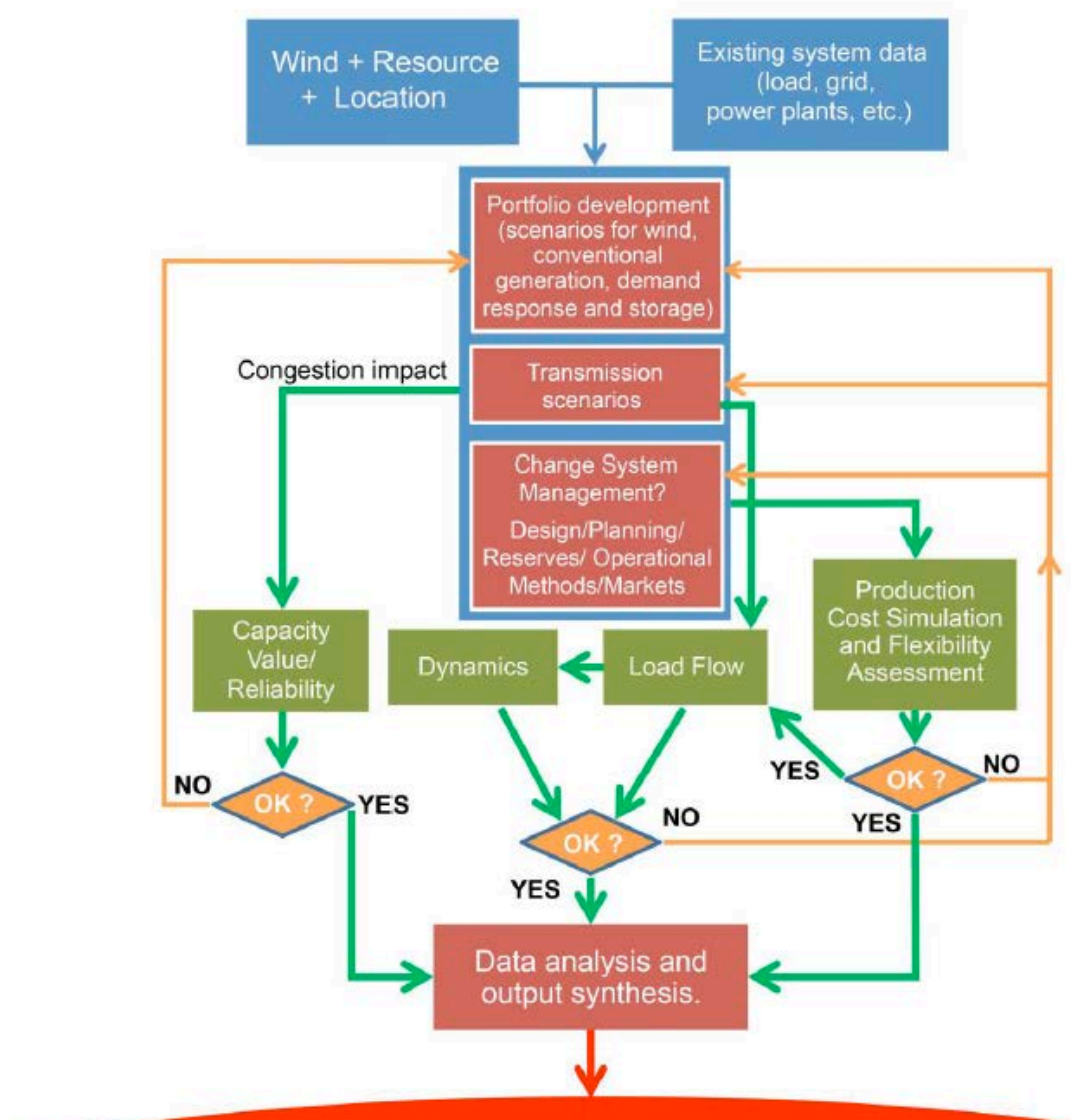

$\$$ Fuel $+\mathrm{CO}_{2}$ Impact + Capital + Cycling Costs + Market Implications

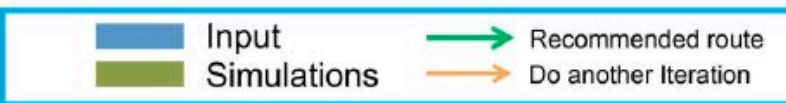

Figure 1. Wind integration study components

Source: Holttinen (2013)

Each section of the roadmap builds on the corresponding section of the IEA expert group report to present the following information:

- Key messages for a first round of integration studies

- Recommendations on how Mexico might best approach the integration study component described in each section including choice of method, assumptions, and input data 
- Additional insights not explicitly captured in the IEA expert group report (e.g., choice of models, considerations for solar power, additional reference citations)

- Examples for further reference.

Additionally, each section will differentiate how Mexican planners might leverage the recommendations in the IEA expert group report to prioritize near-term versus longerterm analyses. The roadmap will help inform SENER and the Council as they work to establish the Clean Energy Obligations and tradable certificates system. Equally important, the roadmap will enable Mexico to start preparing now for the higher penetration levels associated with the $35 \%$ by $2024 \mathrm{RE}$ goal.

Throughout the course of the work developing and finalizing this roadmap, the NREL authors interacted with Mexican stakeholders from SENER, CFE, CENACE, and IIE. Feedback from these stakeholders helped frame the roadmap in the system-specific context of Mexico, providing clarity for how each institution could participate in the range of actions discussed in this roadmap. More detailed feedback provided on a draft version of this roadmap is included as Appendix A.

\section{References}

Archibold, R. (2013). "Mexico's Pride, Oil, May Be Opened to Outsiders." New York, NY: The New York Times. Accessed October 2014: www.nytimes.com/2013/12/13/world/americas/mexico-oil.html?pagewanted=2\& $r=1$.

Holttinen, H., ed. (2013). Expert Group Report on Recommended Practices: 16. Wind Integration Studies. International Energy Agency Implementing Agreement for Cooperation in the Research, Development, and Deployment of Wind Energy Systems. IEA Wind.

"Introduction." (2010). SENER. Accessed September 2014:

www.renovables.gob.mx/portal/Default2.aspx?id=1669\&lang=2.

Llamas, M. (2014). “United States: The Green Side of the Mexican Energy Reform."Jones Day. Accessed September 2014:

www.mondaq.com/unitedstates/x/289124/Renewables/The+Green+Side+of+the+Mexic an+Energy+Reform.

SENER. (2013). "Hitos en la Planeación y el Programa Especial para el Aprovechamiento Energeías Renovables."

"Welcome to Task 25 Homepage." (2014). IEA Wind. Accessed September 2014: www.ieawind.org/task 25.html. 


\section{Input Data}

The building blocks for grid integration studies are time- and place-specific wind and solar resource data. Synchronous time series data allow wind and solar generation to be mapped against electricity demand in order to estimate net load, which defines how the rest of a power system (generation, storage, and demand response) must change to balance the system. Robust resource data will allow system planners to examine multiple scenarios for future generation that include alternative plant locations. The scenarios, in turn, can be used as inputs for production cost models to capture the relationships among forecasting, unit commitment, and dispatch.

Temporal and spatial data also illustrate the smoothing effect of multiple and geographically diverse RE plants. While power output from individual wind and solar plants can fluctuate rapidly due to cloud passage and wind speed variation, the aggregation of RE plant output across a power system reduces the variability, and therefore, the possible costs of integration. The text box to the right includes the general information provided by the IEA expert group report on the smoothing effect of large-scale wind power.

The required data resolution depends on the type of analysis, but at a minimum, hourly wind and solar resource data for one year are needed for likely areas for $\mathrm{RE}$ generation. Data for multiple historic weather years are preferred because they can capture year-to-year weather cycles (such as La Niña/ El Niño). These types of cycles can be important if correlations between hydro power, wet/dry years, and biomass production are of interest. The importance of hydro power in Mexico suggests the selection of high, low, and average precipitation years for analysis.

\section{I Wind and Solar Data}

\section{I.I and 2.I.2 Data Requirements and Wind [and Solar] Generation Data}

NREL just released a high-quality historic solar insolation dataset for Mexico that could be used for integration studies. These data were processed by applying a physicsbased approach to satellite data from geostationary operational environmental satellites 
(GOES). These data include direct normal irradiance and global horizontal irradiance. The high-resolution temporal (30-minute values) and spatial (4-kilometer) data from 2005 to 2012 also include aerosol impacts. The data for 2004 and 2013 will be processed and released before the end of the second quarter of 2015. NREL and GOM have started collaboration to validate these newly released satellite data with ground measurements. NREL is also building a new algorithm to produce one-minute and foursecond interval time series from the 30-minute solar data. This algorithm is available for use with Mexico data (Hummon et al. 2013a; Hummon et al. 2013b). We recommend defining generic solar plant characteristics (panel and inverter characteristics, orientation, fixed/tracking), which, when coupled with the solar resource data and PVWatts (a free NREL tool), would allow the full geographic database to reflect power outputs. These avenues provide a clear path for Mexico to produce sub-hourly solar power data.

Wind resources, in contrast to solar, are more difficult to measure and model. Given the early penetration situation in Mexico, using scaled-up actual wind plant power flow will not capture the geographic diversity effects key to future higher penetration integration analysis. The best approach is to create a simulated dataset based on numerical weather prediction models. Numerical weather prediction models need to be validated against actual measurements (see text box for a detailed description from the IEA expert group report). Large-scale, mesoscale weather models, calibrated with historic weather patterns, can be used to predict wind speeds at potential generation sites in Mexico. Developing such a simulated wind database requires nontrivial financial and human resources.
Excerpt from the IEA expert group report on using measurements to validate numerical weather prediction models:

"If the wind data needed for grid integration studies cannot be derived from actual measurements, it is recommended to use simulated data based on numerical weather prediction (NWP) models. However, measurements still play a crucial role in validating and improving the models and determining parameters used in the simulations.

In these simulations, wind speed on small geographic grids (such as a 2-kilometer square) are extracted at wind turbine hub height and at locations that represent potential future wind plant development. To represent large wind plants, the simulated wind power output from appropriate geographic grid cell locations are combined.

Data is usually needed on an hourly basis. If sub-hourly data are needed, it is common to capture the short-term variability characteristics from actual, operating wind power plants and apply that to future hypothesised wind plants.

When using model data, it is recommended to check the variability of the data by comparing it with measured largescale wind power production data. The simulation should be setup to model the known production data, such that the model results can be compared with the measurements. Care must be taken so that the smoothing effect is modelled correctly. The standard deviation of the time series of variations is one option to check this" (p. 11).

Regarding existing wind data and mapping products in Mexico, IIE has a database of measured wind for specific locations. The Mexico Renewable Resource Atlas has a monthly characterization of wind speed variability. In addition to IIE and SENER, other stakeholders in Mexico that might have resource data include international wind developers; public and private weather modelers or forecasters; and public data measurement networks (e.g., Conagua Comision Nacional Del Agua within the Servicio 
Meteorológico Nacional). ${ }^{3}$ The available base information will be valuable for calibration and initialization of any new modeling efforts that are undertaken. Data from wind developers and private organizations may be proprietary; however, in the United States, NREL has been able to arrange nondisclosure arrangements to use proprietary data in model development and calibration. SENER has commissioned the Engineering Studies Unit of CFE to perform a new wind modeling and calibration study, which shall begin in early 2015 and continue for 18 months. The data produced by this study could potentially match the resolution of the solar database developed by NREL in order to facilitate simultaneous use for modeling purposes.

While expensive and time-consuming to generate, wide-area, internally consistent simulated historic resource datasets are critical to performing grid operational modeling. Because modeling efforts can take up to one year or more, an early start can more quickly allow subsequent grid integration analyses that are contingent on these data.

As part of NREL technical support visits, Vestas has presented information about its proprietary mesoscale model and associated results for Mexico for its commercial site prospecting activities. Given the cost, level of effort, and time frame for developing a new model, one potential avenue for SENER is to develop acceptable terms of agreement with Vestas that would allow use of their modeling results in a broad-scale Mexican integration study. We recommend further exploring this idea, too, as existing model results could significantly shorten the grid integration analysis time window.

\section{Cost Ranges}

Solar synchronized time series data are under production for Mexico as described above. Once scenario locations and plant characteristics are defined, producing solar power data for grid integration analyses will be inexpensive.

In NREL's experience, wind datasets can cost an order of magnitude more than solar datasets. NREL procured datasets for its U.S.-based studies from private firms that use their own adaptations of large-scale, national weather service-scale models. Example companies that perform high-resolution wind historic interpolations and projections in the United States include AWS Truepower, 3Tier, and Windlogics. Recent NREL experience is that a U.S. nationwide, 10 minute, 2-kilometer dataset representing wind speeds at 30-200 meters above ground level can be purchased for around $\$ 2,000,000$. This 2007-2012 U.S. modeling effort is nearly complete, and NREL provided staff to validate the model at an approximate cost of an additional $\$ 150,000$. Modeling gridded data at necessary spatial resolution can be costly, but improvements in computing power and models have brought down costs.

\section{Examples}

For an example of an integration study, see NREL's Western Wind and Solar Integration Study (WWSIS) website at www.nrel.gov/electricity/transmission/western wind.html.

\footnotetext{
${ }^{3}$ For more information, see: smn.conagua.gob.mx.
} 
Phase 2 (WWSIS-2) results are available in The Western Wind and Solar Integration Study Phase 2 at www.nrel.gov/docs/fy13osti/55588.pdf.

For an example of a wind dataset, see NREL's "Western Wind Data Set" website at www.nrel.gov/electricity/transmission/western wind methodology.html.

For methods of developing sub-hourly solar data, see Sub-Hour Solar Data for Power System Modeling from Static Spatial Variability Analysis at www.nrel.gov/docs/fy13osti/56204.pdf.

\section{I.3. Wind [and Solar] Forecast Data}

As stated in the IEA expert group report, wind and solar forecast errors are needed for reserve analysis and production cost modeling, but not for capacity credit or transmission related analyses. The report contains discussion of wind forecast error values from actual experience. There are excellent representations of forecast accuracy as a function of plant geographic spread and forecast time horizon. The report highlights the need to pay particular attention to rare, extremely high forecast errors (often driven by broad-scale, synoptic weather events).

Ideally, for production cost modeling, wind forecast data of a historic weather yearmatched with electric load forecast data-will capture key correlations for operational production cost modeling. Producing weather-dependent, historic, synthetic forecast time series has proven very difficult (Lew et al. 2013). As a result, many integration studies simply use actual forecast error statistics applied to the developed resource time series data.

Wind forecast accuracy improves within six hours of delivery. Presumably, Mexico's wholesale market post-reforms will allow intraday revisions to schedules. The timing of these revisions will dictate what types of forecast data need to be developed for production cost modeling.

Similar historic actual forecast error data for solar power are not as widely available, but that is rapidly changing. For NREL's WWSIS-2 grid modeling studies, the less accurate solar radiation prediction from the mesoscale weather model was used as a forecast for the satellite picture-derived radiation dataset. Monitoring developments of evolution in forecast methodologies through venues such as the Utility Variable-Generation Integration Group (UVIG) annual forecasting workshop is recommended.

Recent DOE-sponsored wind and solar forecast improvement projects are coupling private forecast providers with the national weather resources at the National Oceanic and Atmospheric Administration (NOAA n.d.). These efforts and others suggest that integration studies that look ahead 20-30 years should assume a higher forecasting accuracy than today.

Beyond fundamental modeling needs, which are not specific to Mexico, there are some key Mexico-specific actions to communicate that may help RE integration. With the move toward independent power producers, awareness of anticipatory and real-time 
operating data is critical to power system operations. A key action that SENER, CRE, and CFE can take today is to ensure that interconnection agreements and power purchase agreements (PPAs) include requirements to provide forced outage data and real-time generation and metrological conditions. These kinds of data are often used by grid operators to inform their own centralized forecasts-independent of plant-by-plant decentralized power forecasts provided by each wind and solar plant. For more information on centralized and decentralized forecasting to accommodate variable RE, see Status of Centralized Wind Power Forecasting in North America (Porter and Rogers 2010) and NERC IVGTF Task 2.1 Report: Variable Generation Power Forecasting for Operations (North American Electric Reliability Corporation 2010).

Another potential concern for CFE is generation from self-suppliers. If this generation continues to be a significant fraction of power system generation, SENER, CRE, and CFE might want to address requirements to provide performance data to inform grid operator centralized forecasting. To the extent possible, grid integration scenario development and resource modeling should capture self-generation power delivery and forecasts.

\section{I.4 Wind Turbine (and Solar PV) Capabilities}

Data on wind turbine capabilities described in this section of the IEA expert group report inform transmission voltage control, dynamic stability, and fault response modeling, which are covered in Section 6.

For clarification, active power load flow and reactive power voltage stability capabilities are near-term grid concerns because specific issues can potentially arise in the network due to plant locations, even at early RE penetrations. Fault ride-through capabilities are near- to intermediate-term grid concerns. For more information on the evolution of grid codes to accommodate wind energy, see Code Shift: Grid Specification and Dynamic Wind Turbine Models (Ackermann et al. 2013). NREL's discussions with SENER, CFE, and CRE suggest a strong interest in revising grid codes (now referred to as General Rules for Interconnection in Mexico) to reflect expectations of wind turbine and PV inverter capabilities. Near-term requirements for capabilities will likely include fault ridethrough, provision of reactive power, and possibly automatic generation control (AGC) for wind turbines. AGC has been effective, for example, in Colorado in reducing the magnitude of curtailments by setting conventional generation to minimum levels and using wind plants to provide the minute-to-minute (secondary) frequency response (Bird et al. 2014).

Longer-term grid code requirements could include inertial response and primary frequency response capabilities. The provision of primary frequency response has recently been added as a requirement in Texas. There, the Electric Reliability Council of Texas (ERCOT) required that all wind turbines that can be retrofitted with governor response do so. The full spectrum of active wind power control capabilities are described in Active Power Controls from Wind Power: Bridging the Gaps (Ela et al. 2014). . 
The General Rules for Interconnection can also address technical requirements that impact the performance of the distribution network for smaller generators connected to lower voltage distribution lines and on the customer side of the meter. Issues include harmonic distortion from inverter switching, protection settings, etc. These issues can be quite important for reliable operation of the system and prevent negative impacts on system load devices. Addressing harmonics and other electrical needs, requirements, and grid codes specific to distributed generation is beyond the scope of this integration roadmap, which addresses operational and reliability impacts on the bulk electric system. For international experience with distributed generator characteristics, needs, and interconnection rule development, see the IEA PV Technology agreement, Task 14 on High Penetration of PV systems in Electricity Grids (http://www.ieapvps.org/index.php?id=58\#c92). A valuable summary of DG issues is included in Braun et al. (2011 and 2012).

\subsection{Load Data}

The collection of historic load data and grid planners' projections of future demand is presumably already well-established at CFE. However, NREL and other grid integration modelers have found that operational load forecast data, used for unit commitment and reserve determination, may not be archived. Historically in the United States, operators have addressed load forecast errors by deploying operating reserves.

Historic load forecast errors are informative for production cost modeling because they can be combined with wind and solar generation forecast errors to determine an accurate net-load forecast error. Combined, correlations might exist that impact reserve requirements; for example, when weather forecast errors are high, the RE power forecast and load forecasts might be high as well.

In the absence of historic load forecast error data, integration studies have either ignored the effect or used overall load forecast statistics to generate an error where the time series correlation effects are lost. If not already underway, archiving load forecast error in Mexico will be relatively simple. If at all possible, operational projected load should be captured starting now.

Typically, planners scale historic load data uniformly to reflect future demand. However, integration studies that look ahead 20-30 years might consider alternative scenarios in which demand is impacted by factors such as electrification of cars, energy efficiency, and different rates of growth based on geography or other factors. In Mexico, selfgeneration and small producers are affecting CFE-served load and load shape. Operators and planners could benefit from better information regarding their locations and production.

\subsection{Transmission Grid Interconnections}

The IEA report contains relevant discussion pertaining to when transmission network representation should be considered in different integration studies. Mexico's widespread existing and potential RE generation locations (including remote, but potentially concentrated, wind resource development areas), transmission expansion 
plans, and high load growth projections suggest a strong need for transmission analysis.

For operational production cost modeling, many analysts start with "copper plate" assumptions, ignoring transmission limitations, for the sake of simplicity. Given concerns regarding the dispersed nature of the Mexican system, nodal representation of the system may be justified. Interactions with Mexico's power system stakeholders have identified specific transmission concerns related to Oaxaca wind delivery scenarios that show expanded renewable development.

It is our understanding that load flow and voltage stability analyses are routinely performed by CFE with IIE technical support. Therefore, appropriate transmission datasets for existing and planned system expansion already exist.

Given the variable nature of wind and solar generation, international experience suggests expanding the regular worst-case, snapshot transmission cases to examine additional temporally coincident cases, screened for conditions like:

- Most likely wind and solar delivery during peak demand periods

- High renewable delivery during both high and low demand periods

- Low renewable delivery during high demand periods.

Simply using the total nameplate output of all renewable plants as part of a loading case would result in inaccurate overload predictions and potentially unnecessary oversizing of transmission expansion needs. Using the renewable historic datasets for composite wind and solar output can also allow assessment of possible renewable curtailment due to transmission limitations.

\subsection{Power Plant Data}

Accurately characterizing the abilities of the conventional generation fleet is critical to integration analysis. Existing CFE datasets may need some enhancement to completely capture performance factors, such as ramp rates, minimum generation levels, heat rates as a function of load, and emissions rates. If conventional plants have unusually high outage rates, this information is also useful; otherwise, stochastic techniques will be sufficient for modeling forced outage rates. Coal plants that are traditionally used as base load may be able to ramp power output to some degree, but those capabilities may not have been fully characterized in existing datasets.

Ideally, hydro plants are characterized by data on storage levels, water inflow, and any non-power constraints on outflow (e.g., downstream irrigation and ecological needs). In some integration analyses, the historic power flow from hydro units has been used due to lack of constraint data, but this approach means neglecting the potentially large value that hydro flexibility could bring to the system. For Mexico, capturing hydro operational flexibility may be a critical component even for early penetration integration analysis due to the prevalence of hydro power in the country. 
Future fuel prices are difficult to forecast, and uncertainties are often reflected in alternative scenario development. The relative price of gas and coal can significantly impact the economic unit commitment and dispatch merit order, which in turn affects the type and magnitude of flexibility available to respond to variable net load.

As higher penetrations of renewables are modeled (>10\%-20\%), the increased cycling of fossil plants (starting up and shutting down, ramping up and down, and operating at part-load) may raise concerns about wear and tear impacts on conventional generators. More detailed conventional power plant data might be required, including rampingrelated wear and tear; impacts on numbers of hot, warm, and cold starts; and emission factors during ramping.

NREL has included cycling cost analysis as a feature of its recent integration study, the WWSIS-2. Characterizing cycling costs usually builds from detailed studies of existing plants. NREL drew on cost analyses performed by Intertek APTECH to capture high and low maintenance cost ranges for hot/warm/cold starts and ramping (Kumar et al. 2012). Emissions rate variations were also captured in the plant cycling datasets. Some specific data were protected by nondisclosure agreements, but arrangements were made to use data in production cost runs. While overall costs and emissions rates did not change much when cycling was accounted for, the analysis is useful for addressing policy concerns about emissions and identifying individual plants that might cycle more in high RE scenarios. In anticipation of the need to cycle more, as an operational change, some North American utilities are examining plant retirement plans and/or possible retrofits to increase the cycling ability or extend plant life (Cochran, Lew, and Kumar 2013).

\subsection{Demand-side Management and Storage}

Demand-side Management. Beyond traditional conservation and efficiency, examining and utilizing demand response as a source of grid flexibility is in early stages in most grids, presumably including Mexico's.

Although demand response is therefore not often considered in early rounds of production cost modeling (PCM), it can be a low-cost source of flexibility (Hummon and Kiliccote 2014; Cochran et al. 2012). For example, Texas, which has an isolated system somewhat similar in size to Mexico's, has had a positive experience using demand response to provide frequency regulation. Participating loads (industrial customers) move up and down automatically to help maintain frequency at 60 hertz, and supply $50 \%$ of ERCOT's responsive (spinning) reserves. Load has demonstrated the ability to effectively respond within 10 minutes to contingencies. Early consideration of demand response-including potential sources, regulatory framework, and required infrastructure-could be valuable for Mexico.

Assumptions about demand response will impact production cost models. Although the IEA expert group report emphasizes that studies of wind penetration of less than $10 \%$ can probably assume cost-effective integration with an existing operating system, SENER/CRE/CFE might want to begin to evaluate options with increased demand response given its capacity to reduce integration costs. 
Storage. Adding new electrical storage to a system has widespread advantages and uses. However, prior analyses have shown that costs of conventional (pumped hydro) or advanced storage to accommodate penetrations of wind and solar up to $20 \%$ of annual usage are high compared to benefits (Denholm et al. 2013a; Denholm et al. 2013b). We recommend beginning to examine storage opportunities, but not incorporating them in the first round of integration operational studies.

If central station concentrating solar power (CSP) is considered as a future option in RE expansion scenarios, the cost of including or enlarging thermal storage capabilities is generally low (Denholm et al. 2014). Examination in operational integration analysis of the cost benefit analysis of CSP storage could be considered.

\subsection{Mexico-specific Checklist of Recommendations: Input Data}

Recommendations for Mexico on input data for grid integration studies include:

- Leverage existing and forthcoming solar radiation time series data for Mexico to estimate sub-hourly solar power variations for desired locations and deployment scenarios. Invest early in the development of a large-scale mesoscale weather model to predict wind speeds across Mexico's geography. Calibrate this model using data from entities such as IIE, SENER, international wind developers, public and private weather modelers, and public data measurement methods.

- As an alternative to developing a mesoscale wind model specifically for GOM, explore developing an agreement between SENER and Vestas that would allow the use of Vestas's proprietary mesoscale model results in SENER's broad-scale integration studies. This route could potentially save significant time and money and thereby significantly shorten the grid integration analysis time window.

- Participate in the UVIG annual forecasting workshop and similar venues to gain insight into the evolution of wind and solar forecast methodologies. Consider expanding Mexico's representation in IEA Wind to include participation in Task 25 by appropriate representatives from SENER, CENACE, CFE, and IIE. While beyond the scope of this roadmap, IIE and other Mexico stakeholder concerns regarding distribution system impacts of rooftop and other customer sited PV systems have been examined and addressed in the IEA Photovoltaic Power Systems Programme (PVPS) Task 14 on High Penetration of PV Systems in Electric Grids. Mexico is part of the PVPS, but expanding active participation into Task 14 activities is recommended.

- Tie unit commitment and economic dispatch modeling analysis and related input data requirements to the reforms being considered in the post-reform wholesale market (e.g., the time intervals relevant to forecasting errors should match unit commit reschedule and gate closure times).

- Ensure interconnection agreements and PPAs with independent power producers include requirements to provide forced outage data and real-time generation and metrological conditions to inform centralized forecasting by grid operators. 
- Develop requirements for self-generators to provide performance data and forecasts to grid operators to inform centralized forecasting, grid integration scenario development, and resource modeling.

- Consider revising grid codes to reflect expectations for wind turbine capabilities. In the near term, these capabilities might include fault ride-through, provision of reactive power, and possibly AGC. In the longer term, capabilities might include inertial response and primary frequency response.

- IIE commented that CENACE has an informational database with historical hourly demand forecasts and actual demand by control area. If possible, begin archiving sub-hourly data.

- For integration studies that look 20-30 years in the future, consider including demand scenarios beyond simply the uniform projection of historic load, such as those that account for electrification of cars, energy efficiency, or different growth rates.

- Given concerns regarding the dispersed nature of the Mexican transmission system, evaluate the need to use nodal representation for transmission analysis as an alternative to standard "copper plate" assumptions (which may ignore transmission limitations).

- Expand load flow transmission scenario cases beyond the traditional worst-case snapshot transmission cases to examine additional temporally coincident cases that screen for a variety of wind and solar power delivery and electric load combinations.

- Use the developed wind and solar historic variability datasets for composite wind and solar output (rather than simply the total nameplate output of all plants) to assess possible renewable curtailment due to transmission limitations.

- IIE commented that existing CENACE datasets in its short-term planning model contain fossil plant performance factors such as ramp rates, minimum generation levels, heat rates as a function of load, minimum up times and minimum down times. It is necessary to enhance combined cycle plant data related to dead zones, feasible transitions between configurations, and minimum and maximum time that plants must remain on a certain configuration.

- CENACE databases contain detailed data of both hydroelectric plant models and hydroelectric systems. It is, however, necessary to update some of these data in order to improve the results of the flexibility studies.

- Mexico could consider developing data on demand response supply curves for production cost models to evaluate as a potential mitigation measure to reduce integration costs, particularly if conventional plant flexibility is insufficient or wind and solar curtailment levels are excessive. 


\section{References}

Ackermann, T.; Ellis, A.; Fortmann, J.; Matevosyan, J.; Muljadi, E.; Piwko, R.; Pourbeik, P.; Quitmann, E.; Sorensen, P.; Urdal, H.; Zavadil, B. (2013). "Code Shift: Grid

Specifications and Dynamic Wind Turbine Models." Power and Energy Magazine, IEEE (11:6); pp. 72-82. Accessed October 2014:

http://ieeexplore.ieee.org/stamp/stamp.jsp?tp=\&arnumber=6634510.

Bird, L.; Cochran, J.; Wang, X. (2014). "Wind and Solar Energy Curtailment: Experience and Practices in the United States." NREL/TP-6A20-60983. Golden, CO: National Renewable Energy Laboratory. Accessed October 2014: http://www.nrel.gov/docs/fy140sti/60983.pdf.

Braun, M.; Stetz, T.; Brundlinger, R.; Mayr, C.; Hatta, H.; Kobayashi, H.; Ogimoto, K.; Kroposki, B.; Mather, B.; Coddington, M.; Lynn, K.; Graditi, G.; Woyte, A.; MacGill, I. (2011). "Is the Distribution Grid Ready to Accept Large Scale Photovoltaic Deployment? - State of the Art, Progress and Future Prospects." 26th European Photovoltaic Solar Energy Conference: Proceedings of the International Conference, 5-9 September 2011, Hamburg, Germany. Munich, Germany: WIP-Renewable Energies pp. 3840-3853; NREL/CP-6A00-54390. Accessed September 2014: http://dx.doi.org/10.4229/26thEUPVSEC2011-5DP.3.1.

Braun, M.; Stetz, T.; Brundlinger, R.; Mayr, C.; Ogimoto, K.; Hatta, H.; Kobayashi, H.; Kroposki, B.; Mather, B.; Coddington, M.; Lynn, K.; Graditi, G.; Woyte, A.; MacGill, I. (2012). "Is the Distribution Grid Ready to Accept Large-Scale Photovoltaic Deployment? State of the Art, Progress, and Future Prospects." Progress in Photovoltaics: Research and Applications Special Issue: 26th EU PVSEC, Hamburg, Germany, 2011. 20 (6); pp. 681-697; NREL/JA-6A00-57003. Accessed August 2014:

http://dx.doi.org/10.1002/pip. 1204.

Cochran, J.; Bird, L.; Heeter, J.; Arent, D. J. (2012). Integrating Variable Renewable Energy in Electric Power Markets: Best Practices from International

Experience. NREL/TP-6A20-53732. Golden, CO: National Renewable Energy Laboratory.

Cochran, J.; Lew, D.; Kumar, N. (2013). "Flexible Coal: Evolution from Baseload to Peaking Plant." NREL/BR-6A20-60575. Golden, CO: National Renewable Energy Laboratory. Accessed October 2014: www.nrel.gov/docs/fy14osti/60575.pdf.

Denholm, P.; Jorgenson, J.; Hummon, M.; Palchak, D.; Kirby, B.; Ma, O.; O'Malley, M. (2013a). Impact of Wind and Solar on the Value of Energy Storage. NREL/TP-6A2060568. Golden, CO: National Renewable Energy Laboratory.

Denholm, P.; Jorgenson, J.; Hummon, M.; Jenkin, T.; Palchak, D.; Kirby, B.; Ma, O.; O'Malley, M. (2013b). Value of Energy Storage for Grid Applications. NREL/TP-6A2058465. Golden, CO: National Renewable Energy Laboratory. 
Denholm, P.; Wan, Y. H.; Hummon, M.; Mehos, M. (2014). "Value of CSP with Thermal Energy Storage in the Western United States." Energy Procedia - Proceedings of the SolarPACES 2013 International Conference, 17-20 September 2013, Las Vegas, Nevada. 1622-1631. NREL/CP-6A20-60027. Accessed October 2014: http://dx.doi.org/10.1016/j.egypro.2014.03.171.

Hummon, M.; Weekley, A.; Searight, K.; Clark, K. (2013). Downscaling Solar Power Output to 4-Seconds for Use in Integration Studies: Preprint. NREL/CP-6A20-60335. Accessed November 2014: http://www.nrel.gov/docs/fy14osti/60335.pdf.

Hummon, M.; Ibanez, E.; Brinkman, G.; Lew, D. (2012). Sub-Hour Solar Data for Power System Modeling From Static Spatial Variability Analysis:Preprint. NREL/CP-6A2056204. Accessed November 2014: http://www.nrel.gov/docs/fy13osti/56204.pdf.

Hummon, M.; Kiliccote, S. (2014). "DR Resources for Energy and Ancillary Services in the West." NREL/PR-6A20-60165. Golden, CO: National Renewable Energy Laboratory.

Kumar, N.; Besuner, P.; Lefton, S.; Agan, D.; Hilleman, D. (2012). Power Plant Cycling Costs. NREL/SR-5500-55433. Golden, CO: National Renewable Energy Laboratory. Accessed October 2014: www.nrel.gov/docs/fy12osti/55433.pdf.

Lew, D.; Brinkman, G.; Ibanez, E.; Florita, A.; Heaney, M.; Hodge, B-M.; Hummon, M.; Stark, G.; King, J.; Lefton, A.; Kumar, N.; Agan, D.; Jordan, G.; Venkataraman, S. (2013). The Western Wind and Solar Integration Study Phase 2. NREL/ TP-550055588. Accessed November 2014: http://www.nrel.gov/docs/fy13osti/55588.pdf.

North American Electric Reliability Corporation. (2010). "NERC IVGTF Task 2.1 Report: Variable Generation Power Forecasting for Operations." Princeton, NJ: NERC.

Accessed October 2014: http://variablegen.org/wpcontent/uploads/2013/01/Variable Generation Power Forecasting for Operations.pdf.

Porter, K.; Rogers, J. (2010). "Status of Centralized Wind Power Forecasting in North America." NREL/SR-550-47853. Golden, CO: National Renewable Energy Laboratory. Accessed October 2014: www.nrel.gov/docs/fy10osti/47853.pdf.

"Wind Forecast Improvement Project (WFIP)." (undated). Washington, DC: NOAA. Accessed September 2014: www.esrl.noaa.gov/psd/psd3/wfip/. 


\section{Portfolio Development and System Management}

The portfolio development and system management section of the flow chart depicted in Figure 1 represent processes where SENER, CFE, and CRE can define a baseline, frame the analysis, and capture institutional practices that will be addressed. All the best practices for grid integration can be assessed at this stage: diversifying locations of RE expansion, strengthening transmission grids, institutionalizing market structures to incentivize the provision of flexibility, shortening dispatch intervals from hourly to subhourly, increasing the cycling of thermal plants, and shifting from static to dynamic reserves, among others.

In the near-term, an initial grid integration study could model the existing system with slightly larger capacity and today's operational practices to evaluate the impacts of wind and solar growth. However, likely cost-effective changes to operational practices could be incorporated into portfolio development and system management scenarios. These practices include shortening unit commitment windows, performing sub-hourly dispatch, and incorporating forecast procedures. If, under these scenarios, system operators cannot maintain reliability at a reasonable cost, then SENER, CFE, and CRE can return to this section and the other publications referenced therein and review options for additional sources of flexibility.

\section{I Generation Portfolio and Transmission Scenarios}

The key considerations in establishing the scenarios for an integration study are described in the IEA expert group report and are worth repeating here:

- "What kind of system is being studied—-the current system or a future scenario or scenarios?

- How wind power is added-replacing some existing generation, adding to an otherwise static system, adding simultaneously with a block load of same energy content, or through a portfolio development (possibly optimization) process.

- Assumptions regarding available flexibility, both technical and institutional." (Holttinen 2013, p. 26).

State-of-the-art expansion generation and transmission planning incorporates many elements in optimization models, including spatial and temporal aspects of change and the availability of new technologies such as aggregated demand response. Such planning also covers time ranges from power system operational levels (e.g., seconds) to decades using a breadth of techniques.

One key difference between state-of-the-art planning and traditional planning is the use of levelized cost of energy (LCOE) ${ }^{4}$ In contrast with conventional power plants, wind

\footnotetext{
${ }^{4}$ Traditional generation expansion planning builds upon load growth assumptions and expected retirements. Single-node transmission modeling is common, although including some regionality captures differences in fuel price and demand growth. LCOE evaluations for various technologies are then used to plan generation expansion.
} 
and solar resource intensity is not uniform and is very location-specific. Therefore, single LCOE calculations are not accurate for wind and solar. Calculations to evaluate least-cost generation need to capture variations in resource intensity. Moreover, evaluations of plant siting might also include costs to add transmission to reach wind and solar if plants are sited in remote locations. The LCOE for electricity delivered to each interconnection point varies more broadly for wind and solar than conventional plants. Finally, wind and solar generation output vary over time, so evaluations of expansion options might also include time characterizations of delivery matched to electric demand. In sum, with wind and solar futures, more complete economic and physical system operational and planning modeling must be performed.

Establishing parameters for conventional units is equally important. For example, we understand that for economic reasons, Mexico is undergoing a process to phase out existing oil-fired generation and replacing this capacity with gas generators. Much of the United States has expanded gas generation as well, including California. At the time of rapid gas expansion, California grid planners did not anticipate aggressive policies to support RE or the associated rapid growth of wind and solar generation. Gas projects were selected primarily on bus-bar LCOE criteria, yet these high efficiency units do not have good ramping characteristics. Now, California is studying possible retrofits of the gas fleet to accommodate ramping needs for a system with high RE. Mexico could consider defining two scenarios for oil-fired replacements-one where the highest efficiency gas plants dominate and another that prioritizes gas plants designed to ramp.

\section{Creating Scenarios}

Because SENER plans to expand both generation and transmission, several approaches can help optimize locations and reduce costs. One approach is to use an expansion planning tool that represents potential wind and solar resource supply regions at high spatial resolution and captures the associated transmission costs and values in the LCOE. The example that we presented by phone in January 2014 is the Regional Energy Deployment System (ReEDS). ${ }^{5}$ ReEDS can produce scenarios of electricity system development through 2050 that reflect a range of policy, technology, and economic conditions (Short et al. 2011). For example, the U.S.-based WWSIS-2 used ReEDS to help define alternative deployment scenarios. SENER could use such a tool to estimate plant locations and likely costs of meeting a $10 \%$ RE generation target. Although this tool is specific to the United States, SENER could consider building a tool like this specific to Mexico, or alternatively, work with U.S. modelers to integrate Mexico into a North American model (NREL is currently expanding the U.S. ReEDS model to include Canada).

Another capacity expansion model is the Resource Planning Model (RPM) (Mai et al. 2013). RPM is an hourly chronological model (for a subset of hours per year) that considers grid integration of renewable resources based on transmission and interconnection availability and costs, renewable resource limits and output characteristics, and dispatch options for conventional generators. Whereas ReEDS is

\footnotetext{
${ }^{5}$ For more information, see: www.nrel.gov/analysis/reeds/description.html.
} 
designed to explore long-range shifts in infrastructure due to policy or technological development (focusing on the 2030-2050 timeframe), RPM facilitates the exploration of shorter-term and transitional issues (i.e., in the 2020-2030 timeframe). RPM's flexible platform can be adapted to various regions while ReEDS is a wide-area model that better supports modeling of long-distance interactions and national policies. Due to its smaller geographic and temporal focus, RPM supports high fidelity within the modeling system (e.g., by modeling plants as individual units and enabling fully-resolved transmission modeling within computational limits). The model can provide insight into questions such as how alternative generation sources might replace the functions of existing power plants; how the addition of new transmission lines might facilitate new generation sources; and how state-level incentives might impact the power system. A relatively new model, RPM has been used to model the power system in Colorado and is currently being developed for other balancing areas in the western United States. SENER could consider using RPM to build a standalone model for Mexico to facilitate short- to medium-term capacity expansion planning, potentially as a complement or alternative to a longer-term national planning model like ReEDS.

To help inform the most appropriate model (ReEDS, RPM, or other models), it will help to first assess the key questions that SENER would like to answer. For example:

- Is SENER interested in a top-down, high-level perspective or a detailed engineering model?

- Should the model inform siting for the development of specific projects (transmission and generation) or provide a general sense that renewable deployment in one region of the country would likely require less transmission than deployment in another?

- Is the audience primarily utility staff and power engineers or policymakers?

- Is the focus more on transmission or generation?

- What planning horizon is of most interest (10-20 year planning or 40-50 year scenario analysis)?

- What technologies are of most interest? Wind and solar or the full suite of RE technologies?

- What types of data are available? Individual line and unit information (including minimum generation, voltage, capacity, heat rates, emission rates, etc.)? What types of RE data are available? Hourly or annual?

Developing input data and adapting the ReEDS and/or RPM models for Mexico would take a significant amount of effort, which could potentially fit under EC-LEDS additional capacity building work. Having a Mexican modeler in direct interaction with NREL for several months to a year could be a strategy. Both models could provide planning insights well beyond definitions of expansion scenarios for unit-commitment and economic dispatch (UCED) production cost modeling.

In selecting alternative generation expansion scenarios, stakeholders can consider creating contrasting scenarios to examine operational cost differences. For example, a least-levelized cost option could be a large, centralized RE plant (e.g., a PV solar park) along a transmission corridor. This scenario could be compared with central plants that 
are situated in multiple, geographically diverse locations, and with distributed generation, such as rooftop PV. Each of these scenarios would impact system operations differently, primarily due to the variability that gets smoothed out over broader geographic areas.

Transmission expansion scenarios also depend on factors beyond least-levelized cost (co-optimized with generation expansion). Key complicating factors include difficulties siting lines (e.g., due to lack of eminent domain or public opposition) and plans for cost allocation and recovery. For example, in Mexico, network transmission expansion costs must be approved under the federal budget process for CFE, and costs are not directly allocated to electric rates as in other countries. Thus, budgets for transmission must compete against other budget priorities. For the expansion scenarios, picking less energetic sites closer to load could be more readily implementable-even if not least cost-if transmission expansion budgets are limited.

Key to development of expansion scenarios is stakeholder vetting, including input from CFE planners, operators, and CRE, among others.

\section{Implementing Expansion Plans}

Traditionally in the United States, planning for transmission expansion follows proposals for new generation; funding for transmission cannot be secured without agreements with generators to use the lines. The planning challenge arises with the mismatch of development times between generation (a few years) and transmission (closer to a decade) assets, and therein lies the chicken and egg dilemma. Wind developers do not want to commit to developing new generation if there is a risk that transmission will not be built, and transmission cannot be financed without commitments by wind generators.

A new planning approach is to evaluate likely sites for RE development, called renewable energy zones, and finance the transmission in advance to facilitate long-term generation development. This planning process can improve the efficiency of transmission build-out by financing higher voltage transmission lines that are needed for long-term RE targets (e.g., 20 years) and minimizing line locations that require new rights-of-way. The process improves generation efficiency by optimizing development locations based on both RE resource quality and transmission costs. SENER can explore regulatory and legislative options for a renewable energy zone that aligns with the Secretaría de Hacienda (Mexico's ministry of finance) budgeting-and perhaps finance transmission-through the use of CFE rate revenues.

The overall approach to creating a renewable energy zone would approximately follow these steps:

1. Identify locations where development is likely due to wind and solar resource quality. For example, using IIE's monthly resource data, SENER can create an initial screening of likely generation areas and associated electricity production based on location (e.g., applying filters based on proximity to transmission, excluding locations where development is administratively prohibited or 
technically challenging, etc.). The Geospatial Toolkit, ${ }^{6}$ which uses GIS data, is one possible tool.

2. Examine existing transmission line commitments and ratings, and scope possible line upgrades and new corridor needs.

a. Use temporal profiles of RE generation to evaluate line loadings. For example, the RMATS process (Colorado/Wyoming) looked at historic actual line usage and matched same-year wind generation profiles for prospective plants. For much of the year, the delivery times of wind matched available capacity of lines despite the fact that the rated capacity was already "committed" based on peak demand periods. In addition, RE resource diversity means the line does not have to be designed for the sum of all nameplate capacity. Realistic coincident generation is usually much lower.

b. Use dynamic line ratings to evaluate the need for upgrades. Line rating procedures are often static, or seasonally adjusted, which yield conservative numbers based on worst-case factors including ambient temperatures and wind speed (which affects the temperature of thermally limited lines). Better knowledge of actual conditions (e.g., through temperature and line sag sensors) will allow dynamic line rating and allow increased power flow for much of the year.

3. Plan prospective build-out scenarios from RE goals, and "right-size" lines for long-term growth. Right-size might mean that the transmission system is overbuilt in early stages, but ultimately is lower cost and experiences lower losses than multiple lower voltage lines. Build-out scenarios could include options like big towers that can accept additional conductors in stages.

4. Begin "open season" process for line needs, tying funding certainty to meeting renewable energy zone designations.

5. Conduct a public process that incorporates public feedback on line locations (see Cochran et al. 2012, pp. 113-114, for a detailed discussion of the approach taken by ERCOT in Texas for its line construction).

\subsection{Operational Practices and Markets}

This section of the IEA expert group report reemphasizes that analyses of low penetration levels (less than 5-10\%) can start by modeling current, well-established operational practices. However, notional Mexican goals of around $10 \%$ wind and $1 \%$ solar slightly exceed this general guideline. With the ongoing electric sector reform, there is an opportunity to design new operational practices and to establish markets that would assist in the integration of renewables. Shifting to sub-hourly dispatch, integrating forecasting into unit commitment decisions, and instituting dynamic reserve practices are a few changes that could yield strong economic benefits and therefore could be evaluated and captured in an integration study.

\footnotetext{
${ }^{6}$ For more information, see: www.nrel.gov/international/geospatial toolkits.html.
} 
Key stakeholders in determining what operational practices and markets to examine include grid operational specialists from the National Power Control Center (CENACE), grid planners from CFE, and market reform and design specialists from SENER and CRE.

For even higher penetrations, if the production cost simulations suggest that reliability cannot be cost-effectively achieved based on these modified practices, then additional sources of flexibility can be considered, and these sources are well-documented in other publications (Cochran et al. 2012; Holttinen et al. 2013; Miller et al. 2013; Porter et al. 2012; Denholm et al. 2011).

For example, modifications to the proposed wholesale market design could be assessed. Market design ${ }^{7}$ serves a critical role in high RE power systems by helping to create financial incentives and compensate providers justly for attributes and performance necessary to maintain a stable grid (Cochran et al. 2013). Example attributes that might be valued in high $\mathrm{RE}$ power systems include ramping up and down quickly (e.g., in response to changes in variable RE output) and running at low minimum generation levels (e.g., when RE output is strong but demand is low). A market design analysis would evaluate the impacts of increasing variable RE on, for example: day ahead markets (e.g., prices, participants, congestion costs), imbalance markets, ancillary services markets, and long-term adequacy (due to changes in dispatch order and prices that will come with higher RE). Such an analysis would also look at changes that could be made to market designs to improve the efficiency and performance of necessary services.

An analysis of market design will help address questions such as:

Adequacy

- What are the projected revenues of different generation classes?

- Of the different types of markets and options (e.g., capacity markets, capacity Energy payments, scarcity pricing), which fit best with investor requirements?

- How does increasing demand response affect real-time prices (e.g., locational marginal prices)?

- What are the criteria by which price and market mechanisms to reward flexibility are evaluated in an operational setting?

Ancillary Services

- Would a market product for flexibility attract sufficient market depth to avoid market power?

- How can a market for primary frequency response be designed?

- What is the most efficient division of roles between market and regulated components and which criteria should be used to evaluate this?

\footnotetext{
${ }^{7}$ Wholesale power markets refer to the exchange of energy, ancillary services, and capacity in the bulk power system, which comprises the interconnected resources at the high-voltage level-generation, transmission, and interties to neighboring systems.
} 
In the context of electricity market reform, GOM could consider hosting a workshop specific to market designs that facilitate the integration of variable RE.

\subsection{Reserve Allocation: Estimating Changes Due to Wind Power}

The IEA expert group report identifies reserve allocation as an area of ongoing research, as assumptions can strongly affect UCED production cost results. Two factors specific to Mexico may deserve mention. First, electric sector reform will likely include transitioning CENACE from a part of CFE to an Independent System Operator (ISO). Part of an ISO's mandate typically includes establishing the operating rules and ancillary service markets necessary to procure reserves. As noted in the IEA expert group report, "time steps chosen for dispatch and market operation can influence the reserve requirements" (Holttinen et al. 2013, p. 29). A potential early grid integration modeling priority could be to quantify these time-step effects. The broad international conclusion is that shorter scheduling and sub-hourly dispatch intervals greatly assist integration of increasing penetrations of wind and solar. Shorter intervals allow grid operators to more efficiently respond to changes in net load. Because the magnitude of uncertainty in net load is smaller over a shorter period, 5- or 15-minute dispatch intervals reduce the amount of reserves needed relative to hourly dispatch.

The second factor is Mexico's expected annual electric load growth rate (more than $4 \%$ ), which is higher than in most countries that have performed RE integration studies. The IEA expert group report states, "[i]t should also be noted that an increased level of reserve due to wind power may be supplied by already present conventional generators that are used to supply energy in the non-wind case, and therefore supply less energy and more reserve in the wind case" (Holttinen et al. 2013, p. 30). Mexico's growth rate and concern with declining planning reserve suggests the importance of defining scenarios of future generation mix. Planned additions, retirements, and future flexibility capabilities could considerably influence results.

In addition to these Mexico-specific factors, two more references to reserve allocation in the IEA expert group report, Section 3.3.1, "Recommended Methods" (see recommended methods in the text box on the following page) warrant elaboration. Special attention should be given to 1) defining an acceptable loss of load expectation due to insufficient operational reserves (rather than meeting load absolutely every hour); and a related concern, 2) not holding net-load-related-reserves static across all hours.

At high levels of renewable production, there is no need to hold large amounts of conventional down-ramp capability. Conversely, at low levels of renewable generation, there is no need to hold large amounts of conventional up-ramp capability. A temporal examination could evaluate general patterns and suggest basic variations in reserves (e.g., wind uncertainty might be greatest during spring, thus greater reserves could be held in March and kept lower the rest of the year). At higher RE penetration levels, a detailed analysis would suggest more frequent and finer-tuned changes to reserves.

As an example of the analysis needed to fine-tune dynamic reserves, NREL's reserve methodologies used in the WWSIS-2 study for wind and solar are described in the report titled A Solar Reserve Methodology for Renewable Energy Integration Studies 
Based on Sub-Hourly Variability Analysis, which can be found at: www.nrel.gov/docs/fy120sti/56169.pdf. With wind, the periods of highest variability corresponded to wind production of around $50 \%$ of nameplate capacity - without much regard to time of day. Solar, on the other hand, has one component of variability that is highly predictable in day-ahead scheduling the movement of the solar path. Thus, solar reserves could be driven primarily by cloud-based uncertainty. Reserves practices that consider wind and solar variability and uncertainty are far from established (Hummon et al. 2013), and grid operators in the U.S. and European markets, among other locations, are tailoring ancillary service markets to adapt to variable RE needs. Given the impact on operational cost calculations, we recommend that even the first integration study for Mexico consider the most up-to-date methodologies to conduct reserve analyses.

Excerpt from the IEA expert group report on recommended steps for calculating the impact of wind power on reserve allocation:

1. "The risk of insufficient reserve (i.e., the probability that the scheduled generation plus reserves will not be sufficient to supply the load) must be identified. If the risk is realised, power is imported from neighbouring balancing areas. For example, one might choose to cover $95 \%$ of the variations in net load (load minus wind power) of the balancing area, based on existing operating practice of balancing area reliability metrics in use (like control performance standard in the United States). When considering a whole synchronous system without interconnections, the risk level should correspond to an acceptable loss of load expectation due to insufficient operational reserves.

2. Operating reserves should be calculated for the appropriate time scales, matching existing operational practice. Typically, different types of reserves are associated with (a) automatically responding in seconds-minutes and (b) manually activated in minutes-hour to several hours. When splitting the reserves into separate categories, it is essential not to double-count sources of variability or uncertainty; hence, care should be exercised in this process. If, e.g. the amount of 4hour reserves increases then they normally include also the increase of 2-hour reserves

3. Simple statistical methods can be used to combine the variability and uncertainty from wind and load (and generation); however, assuming that load and generation errors can be represented by normal uncorrelated distributions and using standard deviation values ( $\mathrm{n}$-sigma method) will not be valid. Statistical methods can be altered to take this into account; for example, using a desired level of exceedance or by performing analysis to determine the appropriate distribution.

4. Net-load-related reserves should not be static. The variability and forecast uncertainties depend on meteorological conditions and vary over time. When wind power is generating at a low level of output, there is little need for up-reserve from conventional plants; constant reserve levels will lead to varying risk levels, and conversely, maintaining a constant reliability or risk level will require varying reserves. A further step is to consider the value at risk, which will also change depending on the power system state. It has also been found that wind power variability is generally highest in the mid-output range, as well as during storms, and dynamic reserve methods have been developed that build upon this information (EWITS 2010).

5. The cost and value of these reserves should be assessed in a probabilistic framework. The uncertainties involve the prices of the reserve resources, their probabilities of use, and expected benefits (Menemenlis et al. 2011)" (Holttinen 2013, p. 30-31). 


\subsection{Mexico-specific Checklist: Portfolio Development and System Management}

Recommendations for Mexico on portfolio development and system management include:

- Adapt and exercise a capacity expansion planning tool specific to Mexico that enables the exploration of potential wind and solar plant locations and captures the associated transmission costs to estimate the costs of meeting Mexico's RE targets. ReEDS and RPM are specific examples of existing models developed by NREL that could be adapted to or expanded for Mexico's use.

Regarding this point, in response to a draft of this roadmap report, IIE commented (excerpts from NREL translation):

"CFE has three models developed by the IIE, which could be used for this type of studies:

1) Long-term planning of generation expansion model (PEGyT, utilized by the Under director's office for Programming at CFE) which makes decisions about lowest total cost of investment, operation and externalities;

2) Multi-year stochastic dispatch model (utilized by the Market Operation Office at CENACE); and

3) Hydrothermal Coordination and Unit Commitment (CHT, utilized by the office of Market Operation at CENACE, previously described)."

In response to this comment, the Roadmap authors agree with IIE that,

"The current models that CFE uses have some advantages over the NREL models. The CFE models use with certain sufficient details, the characteristics of the hydroelectric power plants, the storage capacity of the reservoirs, the configuration of the waterways, the spending restrictions in waterways, and the operating limitations of the reservoirs, and the uncertainty of the hydrologic runoffs, which for Mexico are relevant. Additionally, the three models currently utilized by CFE have the information of the various generation and transmission elements of the National Electric System, the storage network, and fuel transport system, already loaded and debugged."

As discussed in Section 2 on Data, and Section 5 on Production Costs, the challenge is in assessing the most expedient course. Options include: 1) translating Mexico-specific electric grid data and practices into models that were developed specifically to account for the unique temporal, stochastic, and spatial characteristics of weather-driven wind and solar generation resources; or 2) adapting existing Mexico specific models that contain relevant existing system characteristics to capture the salient RE characteristics and concerns. 
Several points mentioned by IIE in their detailed comments should be carefully evaluated as part of the determination of the best course. Our familiarity with the models is limited, and we are not in a position at this point to evaluate key aspects mentioned. However, past international experience shows base assumptions can have a large impact, possibly unintentionally. Areas we recommend be examined critically in existing Mexico specific planning models include:

- Year-to year RE resource variations;

- Maximum potential ceilings for renewable energy, by year;

- Minimum generation from clean energy, by year; and

- Stochastic behavior of renewable energy.

Generally, we have found in past work, that translating system specific data and practices into models that are specifically designed to evaluate systems with high penetrations of wind and solar is more expedient and accurate in the long run.

\section{Checklist continued:}

- Consider modeling and examining two scenarios for oil-fired replacements: one where the highest efficiency gas plants dominate, and another that prioritizes gas plants designed to ramp quickly.

- Develop a variety of contrasting alternative wind and solar generation expansion scenarios to examine operational cost differences (e.g., centralized solar versus distributed generation, expanding transmission to remote energetic sites versus minimizing transmission expansion costs).

- Include operational reforms such as shifting to sub-hourly dispatch, integrating forecasting into unit commitment decisions, and instituting dynamic reserve practices into production cost modeling. These scenarios should be designed by grid operational specialists from CENACE, grid planners from CFE, market reform and design specialists from SENER and CRE, and other relevant stakeholders.

- For higher penetrations of RE $(>10 \%)$, if the production cost simulations suggest that reliability cannot be cost-effectively achieved based on the modified practices described above, consider additional sources of flexibility (e.g., demand control).

- Use production cost modeling to quantify the effects of choosing different timesteps for dispatch and market operations to inform the ISO's development of operating rules and ancillary service markets for procuring reserves. Plexos commercial software, and, according to IIE, the existing IIE/CFE Hydrothermal Coordination model have this capability.

- Due to Mexico's relatively high anticipated annual electric load growth, give special attention to defining scenarios for the future generation mix that take into consideration planned additions, retirements, and future flexibility capabilities. The definition of scenarios is part of the current activities of the Subdireccion de Programacion para la elaboracion (Under Director of Programming in the elaboration of the Electric Sector Project and Investment Program - POISE). 
- Define and maintain a constant acceptable loss of load expectation due to insufficient operational reserves across all modeling scenarios to ensure comparability of results.

- Given the potential impact of reserve practices on operational costs, consider examining the most up-to-date methodologies for dynamic reserve analyses.

\section{References}

Cochran, J.; Bird, L.; Heeter, J.; Arent, D. A. (2012). Integrating Variable Renewable Energy in Electric Power Markets: Best Practices from International Experience. NREL/TP-6A20-53732. Golden, CO: National Renewable Energy Laboratory. Accessed September 2014: www.nrel.gov/docs/fy12osti/53732.pdf.

Cochran, J.; Lew, D.; Kumar, N.(2013). "Flexible Coal: Evolution from Baseload to Peaking Plant." NREL/BR-6A20-60575. Golden, CO: National Renewable Energy Laboratory. Accessed September 2014: www.nrel.gov/docs/fy14osti/60575.pdf.

Cochran, J.; Miller, M.; Milligan, M.; Ela, E.; Arent, D.; Bloom, A.; Futch, M.; Kiviluoma, J.; Holttinen, H.; Orths, A.; Gómez-Lázaro, E.; Martín-Martínez, S.; Kukoda, S.; Garcia, G.; Møller Mikkelsen, K.; Yongqiang, A.; Sandholt, K. (2013). Market Evolution: Wholesale Electricity Market Design for 21st Century Power Systems. NREL/TP-6A2057477. Golden, CO: National Renewable Energy Laboratory. Accessed September 2014: www.nrel.gov/docs/fy140sti/57477.pdf.

Denholm, P.; Hand, M. (2011). "Grid Flexibility and Storage Required to Achieve Very High Penetration of Variable Renewable Electricity." Energy Policy (39:3); pp. 18171830. Accessed October 2014: www.sciencedirect.com/science/article/pii/S0301421511000292.

Holttinen, H.; Tuohy, A.; Milligan, M.; Lannoye, E.; Silva, V.; Muller, S.; and Soder, L. (2013). "The Flexibility Workout: Managing Variable Resources and Assessing the Need for Power System Modification." Power and Energy Magazine, IEEE (11:6); pp. 53-62. Accessed August 2014: http://ieeexplore.ieee.org/xpl/articleDetails.jsp?tp=\&arnumber=6634499\&searchWithin\% 3D.QT.flexibility+workout.QT.\%26queryText\%3Dpower+and+energy.

Hummon, M.; Denholm, P.; Jorgenson, J.; Palchak, D.; Kirby, B.; Ma, O. (2013). Fundamental Drivers of the Cost and Price of Operating Reserves. NREL/TP-6A2058491. Golden, CO: National Renewable Energy Laboratory. Accessed September 2014: www.nrel.gov/docs/fy13osti/58491.pdf.

Mai, T.; Drury, E.; Eurek, K.; Bodington, N.; Lopez, A.; Perry, A. (2013). Resource Planning Model: An Integrated Resource Planning and Dispatch Tool for Regional Electric Systems. NREL/TP-6A20-56723. Golden, CO: National Renewable Energy Laboratory. Accessed Jan. 31, 2014: www.nrel.gov/docs/fy13osti/56723.pdf. 
Miller, M.; Bird, L.; Cochran, J.; Milligan, M.; Bazilian, M.; Denny, E.; Dillon, J.; Bialek, J.; O'Malley, M.; and Neuhoff, K. (2013). RES-E-NEXT: Next Generation of RES-E Policy Instruments. NREL/TP-6A20-58882. Golden, CO: National Renewable Energy Laboratory. Accessed May 2014: http://iea-retd.org/wp-content/uploads/2013/07/RESE-NEXT IEA-RETD 2013.pdf.

Porter, K.; Mudd, C.; Fink, S.; Rogers, J.; Bird, L.; Schwartz, L.; Hogan, M.; Lamont, D.; and Kirby, B. (2012). Meeting Renewable Energy Targets in the West at Least Cost: The Integration Challenge. Denver, CO: Western Governors' Association. Accessed August 2014: www.westgov.org/policies/doc download/1602-meeting-renewableenergy-targets-in-the-west-at-least-cost-the-integration-challege.

Short, W.; Sullivan, P.; Mai, T.; Mowers, M.; Uriarte, C.; Blair, N.; Heimiller, D.; Martinez, A. (2011). Regional Energy Deployment System (ReEDS). NREL/TP-6A20-46534. Golden, CO: National Renewable Energy Laboratory. Accessed September 2014: www.nrel.gov/docs/fy12osti/46534.pdf. 


\section{Capacity Value}

\section{I Methods}

Mexico's high expected annual electric growth rate has implications not only for reserve allocations, but for capacity value assessments as well. Because PCM can be costly, Mexico would benefit from evaluating capacity value and resource adequacy of future scenarios as a pre-screen to the more detailed PCM evaluation. If adequacy criteria are not met, scenarios can be revised to increase generation or decrease load before detailed PCM proceeds.

As described in the IEA expert group report, methodologically correct effective load carrying capability calculations require hourly time series of wind and solar power for multiple historic weather years. If the high temporal and spatial resolution datasets needed as inputs for PCM are available, they should also be used for capacity value calculations. However, if the high-resolution wind resource dataset is not yet available, and for the purpose of pre-screening, lower resolution datasets are commercially available (from, e.g., AWSTruepower and 3Tier) at much lower cost. These datasets are often derived from macro- and global weather models, capturing broad regional patterns, but will miss the localized terrain and other factors that influence site-specific wind resource power. If the data limitations regarding site-specific factors are understood, rough pre-screens of resource adequacy could be cost-effective and informative.

IIE in Mexico has been measuring, collecting, and archiving wind and solar resource data measurements for specific locations for years. In addition to being valuable for calibrating the broader, high resolution assessments used to inform PCM, site-specific data can be used as input to approximate capacity credit methods as mentioned in the IEA report.

\subsection{Mexico-specific Checklist: Capacity Value}

- Evaluate capacity value and resource adequacy of future scenarios as a prescreen to the more detailed PCM evaluation. If adequacy criteria are not met, revise scenarios to increase generation or decrease load before detailed PCM proceeds.

- Use high temporal and spatial resolution data, if available, to calculate capacity value. If a high resolution wind resource dataset is not yet available, commercially available lower resolution (and lower-cost) datasets may be used for the purpose of pre-screening. 


\section{Production Costs and Flexibility Assessment}

\subsection{Production Cost Simulation}

This section of the IEA expert group report describes the key modeling issues surrounding production cost simulation of the UCED analysis process. Modeling and electric system adaptations to improve flexibility are discussed and categorized into two groups: operational rules and technologies.

For first-round integration analysis in Mexico, we suggest focusing on operational rules addressing 1) sub-hourly UCED, 2) examination of reserve levels, and 3) consideration of dynamic reserve procurement. At Mexico's anticipated penetration goals, we expect these flexibility measures will be sufficient. However, if this first-round or later higher penetration evaluations of the system show excessive curtailment, iterating back to assess additional operational and physical sources of flexibility is warranted, as described previously.

The CFE electric system is dispatched as a single, synchronous balancing area, and interconnections south and north are currently very limited, so concerns with enlarging the balancing footprint addressed in European and U.S. studies need not be considered. Longer term, increased exchange with adjacent power systems could be considered as a source of flexibility. We also suggest beginning the UCED analysis without considering transmission power flow constraints. Results can then be evaluated against known constraints to determine if iteration back to limit delivery of ancillary services in the UCED modeling is needed.

On the technologies side, suggested first round attention includes 1) incorporating wind forecasting into UCED, 2) accurate representation of fossil and hydro fleet characteristics, and 3) evaluation of wind and solar power curtailment levels when generator flexibility is fully utilized.

Historically, production cost models were designed to model unit commitment and dispatch in hourly time steps. Early wind integration studies that built on these models examined sub-hourly variability through statistical means due to modeling limitations, with these methods seeing varying degrees of success. When models that included sub-hourly capabilities became available, many analysts switched platforms in spite of the increased data challenges to model both renewable resources and generator capabilities. We recommend Mexico's first round integration analysis be performed on a platform that accommodates sub-hourly time steps.

A full review of commercial PCM models is not within the scope of this white paper. NREL's most recent regional grid integration analyses (WWSIS-2 and Eastern Renewable Generation Integration Study), as well as those of several other sponsoring organizations (e.g., California ISO, Midcontinent ISO), have used Energy Exemplar's Plexos sub-hourly modeling platform (CAISO 2010; Bakke et al. n.d.).

Plexos UCED sub-hourly modeling can also be augmented by other tools. NREL's Flexible Energy Scheduling Tool for Integrating Variable generation (FESTIV) models 
system second-to-second automatic generation control for balancing in that time scale. REFLEX, developed by E3, is a stochastic options assessment tool that can use Plexos UCED and examine grid flexibility options. REFLEX has been used to evaluate up to $50 \%$ renewable penetration in California (E3 n.d.). These other tools are part of the continuing advancement in sophistication regarding grid integration with large amounts of wind and solar power. For first-round Mexican analysis, we suggest concentrating on the core sub-hourly UCED modeling.

During the course of collecting comments on this work, interaction with Mexico experts made us aware of the existing Hydrothermal Coordination and Unit Commitment Model (El modelo actual de Coordinación Hidrotérmica y Asignación de Unidades) developed by IIE. It has many of the production cost modeling characteristics identified as necessary for good high penetration RE modeling by the IEA expert group report. IIE represents that the model is designed to:

- Minimize the variable production costs, plus the externalities and the cost of supply failure

- Capture offers to sell energy through the relationship of price or cost versus power generation

- Use data on operating limits to generation units

- Incorporate energy purchase offers and sales offers through international interconnections

- Capture generating unit ramping limitations

- Incorporate minimum required times for operation and stoppage of generating units

- Represent transmission as a nodal network

- Capture transmission restrictions

- Model restrictions in supply of fuels

- Capture rolling and 10-minute reserves' restrictions

- Examine demand control and interruptible loads

- Capture hydro power characteristics like the reservoir's storage capacity and the characteristics of the hydroelectric power plant, the configuration of the waterways, water usage restrictions, and the operating limits of the reservoir

- Incorporate security restrictions due to generation and transmission contingencies.

These capabilities were developed in the context of the historic Mexico electric system, and may capture the hydro characteristics (an important consideration in Mexico) more thoroughly than comparable modeling efforts in other parts of the world. The model, therefore, may provide a valuable building block in going forward toward the recently formulated clean energy goals.

By analogy to similar world-wide efforts, there will be challenges to capturing the salient characteristics of wind and solar power in existing IIE and other traditional models and modeling frameworks that have been used in Mexico. Key modeling and data challenges are likely to include: 
- Integrating multiple time scale wind and solar forecasting into unit commitment, dispatch, and reserves practices

- Capturing geographic diversity impacts and evaluating realistic time series of transmission line loadings

- Adapting the modeling to capture evolving market processes under the sector reforms.

Further evaluation of the adaptability of the Hydrothermal Coordination and Unit Commitment Model is necessary to determine the most appropriate course for Mexico regarding UCED modeling with potential future high penetrations of wind and solar. The advantages of the existing model include ready acceptance, familiarity, and having Mexico-specific conventional generator and operational practice datasets and algorithms already captured. Nevertheless, standardized UCED tools from commercial vendors, such as Plexos, have come a long way in the past several years, evolving to reflect analysis needs associated with many U.S. and international clean energy visions, goals, and potential policies. Transferring appropriate Mexico-specific system practices and transmission and generator characteristics and data may be challenging. Conversion to another modeling platform takes significant effort, but may offer long-term advantages associated with RE-related model advances and support from platform vendors and a peer community (including NREL modelers) who can assist Mexico. We recommend a careful evaluation be performed before committing to a modeling platform choice.

If training on broadly available commercial production cost models is desired, likely participants include grid modelers in CFE, IIE, and potentially SENER, CENACE, and others.

\section{Cost Ranges}

As with creating wind resource datasets, the costs to model production costs are considerable. In the United States, NREL-managed PCM projects have been funded with U.S. Department of Energy federal RE research funds. For the western interconnect, total costs to model three years of grid operations approached \$2 million. These costs did not include the utility and other grid stakeholder support for interaction or the cost of the wind and solar historic weather year resource datasets (the costs of which were discussed earlier in Section 2). Scaled to the size of Mexico's electric system, a total cost of around $\$ 500,000-\$ 1$ million might be expected. One key uncertainty is the availability of comprehensive data on "flexibility" capabilities of Mexico's conventional generators (e.g., ramp rates, minimum generation, off-peak emissions and heat rates).

The costs of the PCM model itself are relatively minor; the major costs are associated with data development and labor to run the models, analyze data, and communicate results. Based on NREL's experiences, a rough breakdown of costs by key tasks is: 


\subsection{Flexibility Assessments as a Pre-PCM Screening Tool}

If flexibility is likely to be a concern, flexibility assessment tools could serve as a prePCM screen to assess whether the planned capacity will be able to respond to shortterm changes in net load. One example of a flexibility assessment tool is FAST2, which IEA developed and presented at the Workshop on Grid Analysis and Policies in September 2013. FAST2 measures the maximum upward or downward change in the supply/demand balance that a power system is capable of meeting over a given time horizon and a given initial operating state (i.e., operation level of different power plants). FAST2 focuses on physical characteristics of the power system.

Another assessment tool is the Insufficient Ramping Resource Expectation tool (Lannoye et al. 2012), which calculates the expected number of observations when the power system cannot cope with changes in net load. This tool includes not only physical characteristics, but allows changes to economic and institutional characteristics as well (e.g., changes to dispatch intervals, market incentives). These tools do not provide the full evaluation of production cost UCED analysis, and they do require some of the same datasets that are time consuming to develop. However, with test case or proxy data from other systems, they can provide insights which could be valuable to SENER to address near-term policy concerns that the existing power system cannot handle the ramping impacts of adding wind and solar to the grid.

Given Mexico's progression toward a cleaner electric system, we recommend that the development of datasets - critically, wind resource time series and conventional generator capabilities and scenario development begin as soon as possible to enable the more detailed UCED modeling post haste.

\subsection{Mexico-specific Checklist of Recommendations: Production Cost Simulations and Flexibility Assessment}

Recommendations for Mexico on production cost simulations and flexibility assessment include:

- For initial integration analysis in Mexico, focus on operational rules addressing 1) sub-hourly UCED, 2) examination of reserve levels, and 3) dynamic reserve procurement. In future integration analyses, Mexico can consider including 
longer-term operational items, such as enlarging the balancing footprint through increased exchange with adjacent power systems.

- For initial integration analysis, prioritize 1 ) incorporating wind forecasting into UCED, 2) accurate representation of fossil and hydro fleet characteristics, and 3) evaluation of wind and solar power curtailment levels when generator flexibility is fully utilized.

- Begin the UCED analysis without considering transmission power flow constraints. Evaluate the results against known constraints to determine if iteration back to limit delivery of ancillary services in the UCED modeling is needed.

- If initial or future integration evaluations indicate excessive curtailment (due to operational limits, rather than abnormal disturbance response needs) within the system, iterate to assess additional operational and physical sources of flexibility beyond those already suggested. Voluntary demand control programs, incentivizing future generation resources for flexibility, tapping hydro or gas storage opportunities, or adding electrical storage technologies can be examined once first round analyses are completed.

- Perform initial models for unit commitment and dispatch on a platform that accommodates sub-hourly time steps. Standardized tools from commercial vendors will readily capture the appropriate generator characteristics and UCED processes, but data development will be required. Existing tools in use in Mexico may be customizable to accommodate this type of analysis. We understand that the Hydrothermal Coordination model is currently being adapted to accommodate sub-hourly time steps and associated operational practices. Data for demand and generation forecasts may also require modification.

- Begin dataset development (critically, for wind resource time series and conventional generator capabilities) and scenario development as soon as feasible to enable timely implementation of the more detailed UCED modeling.

\section{References}

Bakke, J.; Zhou, Z.; and Mudgal, S. (undated). Manitoba Hydro Wind Synergy Study. Midcontinent Independent System Operator. Accessed July 2014:

http://energyexemplar.com/wpcontent/uploads/publications/Manitoba $\% 20 \mathrm{Hydro} \% 20 \mathrm{Wind} \% 20$ Synergy $\% 20$ Study $\% 20 \mathrm{~F}$ inal\%20Report.pdf.

California Independent System Operator Corporation. (2010). Integration of Renewable Resources: Operational Requirements and Generation Fleet Capacity at 20\% RPS. Accessed September 2014: http://energyexemplar.com/wpcontent/uploads/publications/CAISO Study Using PLEXOS.pdf.

"Projects: Other Selected Projects." (undated). Energy+Environmental Economics (E3). Accessed October 2014:

www.ethree.com/public projects/renewables portfolio standard.php. 
Lannoye, E.; Flynn, D.; O'Malley, M. (2012). "Evaluation of Power System Flexibility." IEEE Transactions on Power Systems (27:2); pp. 922-931. Accessed October 2014: http://ieeexplore.ieee.org/stamp/stamp.jsp?arnumber $=06125228$. 


\section{Transmission Grid Simulations: Load Flow and Dynamics}

\section{I Load Flow Simulations}

As noted in the IEA expert group report and the discussion in this paper in Section 2.3, wind (and solar) integration studies require modeling of a range of load flow scenarios beyond what is normally included in a conventional interconnection study. Load flow cases should include not only the "worst-case" scenario (i.e., no wind/high load), but also high wind/low load, high wind/high load, and other cases that will help illuminate the range of new transmission system loading patterns that may occur under high penetrations of wind. An ideal approach is to base the load flow simulation on the actual temporal load profile for at least a full year.

Assessing congestion may be particularly important for Mexico due to the low-capacity, low-density nature of the country's transmission grid. Standard models currently in use for assessing steady-state security and network loading in Mexico can be adapted to ensure that the portfolio and transmission scenarios under consideration do not create bottlenecks.

\subsection{Dynamic Stability Analyses}

For Mexico, dynamic stability is not likely to be an immediate concern related to the integration of RE. Dynamic stability analyses may be necessary if inverter-based wind and solar installations grow rapidly to the point that CFE, CENACE, CFE, AND SENER consider shutting down existing conventional generators. Given Mexico's anticipated load growth, this issue may not arise in the near term, even as RE is added to the system. CFE and IIE engineers and consultants familiar with the Mexican system are already well-positioned to evaluate specific concerns regarding dynamic stability arising from particular system characteristics.

Grid stability and dynamic response to disturbances (faults) with high amounts of inverter-based generation is an emerging area of research. Specific generator modeling frameworks to analyze these issues are difficult to maintain due to rapid evolution of wind and solar generator topology and advanced controls. For example, it can be difficult to validate a generator model. Additionally, grid support capabilities for wind turbines are an emerging technology area and do come at an added cost (Ela et al. 2014). Grid stability and dynamic response is therefore a longer-term assessment priority for Mexico.

Revisions to grid codes could help to anticipate longer-term impacts on dynamic stability as higher penetrations of RE are reached in support of the RE targets and as conventional generators are gradually retired. Nearer-term grid code considerations for Mexico include the option of AGC as well as voltage excursion ride-through capabilities that contribute to power system restoration in the event of disturbances. Additionally, reactive power control will assist with voltage stability issues that may be important on longer, lower voltage transmission lines. 
Additional measures such as full inertial response are also likely to be longer-term considerations that would eventually necessitate dynamic stability analyses. These analyses should assess frequency response capability across the entire system. Generally, declining grid frequency response observed in some systems is due to lack of compensation for capabilities on conventional generators, not the impact of RE deployment. Recent studies have produced promising findings that wind power can actually strengthen overall system reliability and frequency response in an economical manner through active power control (Ela et al. 2014).

Beyond the IEA discussion of wind, PV panel and inverter technologies do not have a spinning rotor with inherent rotating mass, so Active Power Control features cannot be provided without some kind of additional energy storage. Research on systems with high amounts of PV has just recently begun, and understanding the impacts will likely advance quickly. Anticipated Mexican PV deployment rates are likely not high enough for immediate concern.

Note that CSP systems, which are not considered sources of variable renewable electricity, typically use conventional synchronous generators, so no particular dynamic stability issues are endemic to their deployment beyond concerns for any other conventional generator system.

The California ISO and North American Electric Reliability Corporation (NERC) have recently developed recommendations for the CAISO grid (and beyond) for meeting reliability objectives while incorporating large amounts of both wind and solar RE through considerations such as reactive and active power control; inertia and frequency response; and steady-state, short-circuit, and dynamic generic model development (NERC and CAISO 2013). Analysis of 33-55\% renewable penetration scenarios in California has indicated the integration of large amounts of solar PV has the potential to decrease fault response.

The CAISO-NERC recommendations were informed by a detailed grid dynamic response study performed by GE Energy (Miller, Shao, and Venkataraman 2011). Additionally, NREL and GE are currently in the process of examining dynamic response and frequency control issues under high renewables penetration for the full North American Western Interconnect. Results should be available later this year. These cutting edge analyses are breaking new ground with models and simulation in this area.

\subsection{Network Reinforcements}

This section of the IEA expert group report describes the fairly standard iterative process used to evaluate potential transmission system additions. Since there are usually several alternatives that could address most transmission issues, the analysisproblem definition-redefine system (with potential upgrade)-redo analysis cycle is likely used already by CFE, IIE, and CENACE engineers.

The IEA expert group report discusses a complication imposed by increasing renewable penetration - that of many more system states of interest. Different combinations of 
high/low renewables, conventional generation levels, and load states result in different system challenges and issues. Probabilistic approaches are suggested.

In the current Mexican environment, sector restructuring does raise the issue of maintaining and enhancing the capacity for analysis. Network reinforcement is generally the responsibility of the ISO or transmission system operator in competitive electric generation systems. In Mexico, this expertise may reside within IIE and CFE. In the United States, many private consultants augment grid operator, grid planner, and regulatory capabilities. NREL has also used a wide variety of expert consultants to assist with renewable grid integration research.

\subsection{Mexico-specific Checklist of Recommendations: Transmission Grid Simulations}

NREL's technical support through this EC-LEDS work has not highlighted any particular concerns specific to transmission grid simulations. CFE, IIE, and CENACE engineers are in the best position to evaluate if existing system conditions would be strongly impacted by near-term anticipated wind and solar deployments, and additional assessment may be in order.

\section{References}

Ela, E.; Gevorgian, V.; Fleming, P.; Zhang, Y.C.; Singh, M.; Muljadi, E.; Scholbrook, A.; Aho, J.; Buckspan, A.; Pao, L.; Singhvi, V.; Tuohy, A.; Pourbeik, P.; Brooks, D.; Bhatt, N. (2014). Active Power Controls from Wind Power: Bridging the Gaps. NREL/TP-5D0060574. Golden, CO: National Renewable Energy Laboratory. Accessed Jan. 30, 2014: www.nrel.gov/docs/fy14osti/60574.pdf.

Miller, N.; Shao, M.; Venkataraman, S. (2011). California ISO (CAISO): Frequency Response Study. Schenectady, NY: GE Energy.

North American Electric Reliability Corporation and California Independent System Operator Corporation. (2013). 2013 Special Reliability Assessment: Maintaining Bulk Power System Reliability While Integrating Variable Energy Resources-CAISO Approach. Accessed Jan. 30, 2014: www.nerc.com/pa/RAPA/ra/Reliability\%20Assessments\%20DL/NERCCAISO VG Assessment Final.pdf. 


\section{Analyzing and Presenting the Results \\ 7.I Assessing Costs and General Guidance}

The IEA expert group report section on results contains an abundance of cautions. The complexity of power systems and the interactions across the total system from any change are difficult to distill into simple metrics. First-round results should be examined critically, and perhaps initial assumptions or operational parameters embedded in models should be modified. Generation portfolio assumptions on inherent flexibility - and operational practices and market structures to access and deploy that flexibility — will greatly influence results.

Grid integration analyses are important as part of a process of learning and adaptation, as they are in coming up with particular numeric results. A key insight from the report:

"At higher penetration levels, the methods and tools used for planning and operation, like allocation of reserves, need to be adapted. Successful wind integration means changing the operation of the power system from how systems have been traditionally operated" (Holttinen 2013, p. 61).

Mexico stakeholders seem very interested in quantifying wind integration costs. The IEA expert group report highlights the difficulties of such a goal, but helps think through the key issues of 1) how broadly to encompass both costs and benefits, and 2) what the system baseline will be for comparison.

Narrow definitions of integration costs, such as increases in reserve levels or balancing market costs, oversimplify and mask many key assumptions. Total production cost amounts can be compared for different generation scenarios, provided care is taken to maintain a constant level of reliability. However, these numbers are greatly influenced by fuel cost assumptions and associated dispatch decisions.

The Mexican context of increased load growth makes assumptions about future generation mix particularly critical. A capacity credit assessment will help inform assumptions about the generation mix for new peak loads. Comparisons will be very sensitive to the alternative generation mix in the absence of wind and solar. Climateoriented policy goals beg the question: What are the emissions rates of the alternative system, and how should differences be valued?

Integration costs of wind should be put in perspective by comparison to other figures, such as the market value of the wind power. In summary, different alternative future scenarios should be compared from economic, reliability, security, and environmental points of view.

Limitations of the study's results arising from assumptions are best addressed by presenting results of sensitivity analysis and examinations of alternate scenarios. We also suggest iterative processes to evaluate potential transmission upgrades (i.e., if there is too much congestion or curtailment, try additional upgrades or sources of 
flexibility). The IEA expert group report contains list of key assumptions that, if reported, will help in understanding the limitation of the integration study.

A final point not covered in the report is that stakeholder involvement from Mexican grid experts including CFE, IIE, CENACE, CRE, and SENER is critical to ensure validity of inputs, analyses, and results. NREL-run studies in the United States have greatly benefited from a formal Technical Review Committee (TRC) composed of the appropriate grid stakeholders, wind and solar industry, international experts, and study sponsors. The Utility Variable-generation Integration Group has developed "Principles for TRC Involvement," available at http://variablegen.org/wpcontent/uploads/2009/05/TRCPrinciplesJune2012.pdf. We strongly suggest these principles be reviewed and followed from the initial conceptual formulation and study framing, through development of assumptions and scenarios, review and critique of intermediate results, iterative adaptation of inputs, to finalization of results and presentation frameworks.

Experts for Mexico's TRC may seek guidance from the IEA, NREL, and UVIG staff, including those who participated as authors in developing the IEA Recommended Practices on Wind Integration Studies.

\subsection{Mexico-specific Checklist of Recommendations: Analyzing and Presenting Results}

Recommendations for Mexico on analyzing and presenting results of grid integration studies include:

- Compare different alternative energy future scenarios from economic, reliability, security, and environmental perspectives and report key assumptions underlying metrics such as costs, generation mix, emission rates, operational practices, and market structures.

- Present the results of sensitivity analyses to address and communicate limitations of integration studies resulting from the definition of assumptions.

- Involve Mexican grid experts and stakeholders, including CFE, IIE, CENACE, $\mathrm{CRE}$, and SENER, in developing and validating inputs, analyses, and results of integration studies. A technical review committee may be an appropriate mechanism for such engagement. Review and adapt as appropriate the UVIG's "Principles for TRC Involvement" to the entire process of grid integration assessment in Mexico.

- Seek guidance as needed from the international expert community (e.g., IEA, NREL, UVIG staff) to provide input and feedback on Mexico's ongoing grid integration analysis efforts. 


\section{Conclusion}

Conducting grid integration studies in conjunction with RE goal setting is good practice. To support SENER and other stakeholders involved in establishing and meeting Mexico's ambitious RE targets, this grid integration roadmap has provided information intended to supplement and contextualize for Mexico the more general guidance provided in the IEA expert group report. Taken together, we believe these two documents holistically present the key issues and steps that SENER will need to consider in developing a robust and comprehensive renewable electricity grid integration study.

Both the IEA expert group report and this grid integration roadmap provide numerous recommendations related to each component of a grid integration study. The key actions that SENER can prioritize to lay the foundation for a grid integration study for Mexico include:

- Creating or purchasing a mesoscale model of historic wind resources to capture temporal and spatial diversity, which will be needed to correlate wind generation with solar generation and electric load.

- Beginning or expanding efforts to capture input data for grid integration studies (e.g., forced outage and generation by independent power producers; performance data and forecasts for small generators; load forecast errors and operational load; performance data for the conventional and hydropower generation fleet).

- Deciding how to assess expansion scenarios for renewable and conventional generation and transmission. If SENER needs to acquire a new planning model (e.g., ReEDS, RPM), this effort will take time.

- Considering (and including in grid integration modeling) market designs that help integrate RE given the reforms of electricity sector to institute competitive wholesale power markets. Priority designs will likely include sub-hourly scheduling, integration of centralized forecasting to unit commitment and dispatch, and use of dynamic reserves.

- Considering revising grid codes to reflect expectations for wind turbine capabilities, which, in the near term, might include fault ride-through, provision of reactive power, and possibly AGC. 